\title{
Evidence of added value in North American regional climate model hindcast simulations using ever-increasing horizontal resolutions
}

\author{
Philippe Lucas-Picher ${ }^{1,2} \cdot$ René Laprise $^{1} \cdot$ Katja Winger $^{1}$
}

Received: 10 September 2015 / Accepted: 3 June 2016 / Published online: 25 June 2016

(C) The Author(s) 2016. This article is published with open access at Springerlink.com

\begin{abstract}
Commonly termed "added value", the additional regional details gained by high-resolution regional climate models (RCMs) over the coarser resolution reanalysis driving data are often indistinguishable at the $0.44^{\circ}$ grid mesh computationally affordable large CORDEX domains. In an attempt to highlight the benefits of finer resolutions to study the RCM added value, five North American weather phenomena are evaluated in RCM hindcast simulations using grid meshes of $0.44^{\circ}, 0.22^{\circ}$ and $0.11^{\circ}$ with available observations. The results show that the orographic precipitation on the west coast of North America is enhanced and more realistic, with two distinct rain bands in the finer resolution simulation. The spatial distribution of precipitation in August and the high frequency of summer precipitation extremes over southwestern United States reveal that the North American monsoon is improved with increasing resolution. Only the finer RCM simulation shows skill at producing snowbelts around the Great Lakes by capturing lake-effect snow. A comparison of wind roses in the St. Lawrence River Valley indicates that only the finer RCM simulation is able to reproduce wind channeling by resolving complex orography. Finally, the simulation of the summer land-sea breezes by the RCM simulations leads to added value in the diurnal cycle of precipitation over the
\end{abstract}

Philippe Lucas-Picher

plp@sca.uqam.ca

1 Département des sciences de la Terre et de l'atmosphère, Centre ESCER (pour l'étude et la simulation du climat à l'échelle régionale), Université du Québec à Montréal (UQAM), P.O. Box 8888, Stn. Downtown, Montreal, QC H3C 3P8, Canada

2 Département de génie de la construction, École de Technologie Supérieure, Université du Québec, Montreal, QC, Canada
Florida peninsula and the Caribbean islands. Overall, the almost systematic improvements of the finer resolution simulations suggest that higher resolutions, only computationally affordable over smaller domains, might get a higher priority to promote RCM added value.

Keywords Regional climate modeling · Added value . North America $\cdot$ Weather phenomena $\cdot$ Reanalysis

\section{Introduction}

The main goal of dynamical downscaling is to provide additional details beyond what can be obtained by global reanalyses or global climate models (GCMs) that are limited by their coarse resolutions (e.g., Hong and Kanamitsu 2014). This goal can be achieved with high-resolution limited-area nested regional climate models (RCMs) that need to be driven at their lateral boundaries. A major advantage of RCMs is the possibility to be driven by reanalyses, often called "perfect lateral boundary conditions (LBCs)" because the weather conditions come from observations that are assimilated in a model, and thus consist of real past weather states. Using this setup, RCM hindcast simulations can be directly evaluated against observations, not just in a "statistical sense", but also in a "time series sense", thus allowing to perform case studies (Rummukainen 2010).

More than 25 years after the inception of RCMs (Giorgi and Bates 1989), the additional fine-scale details gained by RCMs, commonly termed "added value", are still an issue central to their use for downscaling GCM projections (e.g., Feser et al. 2011; Giorgi and Gutowski 2015; Di Luca et al. 2015). We think it is fair to say that rather modest added value has been found in RCM hindcast simulations driven by reanalyses with grid spacings of around $50 \mathrm{~km}$. The 
CORDEX project (Giorgi et al. 2009) recommended grid mesh of $0.44^{\circ}$ for basic simulations over large continental domains; however some groups were able to downscale using grid spacings finer than $0.44^{\circ}$ (Panitz et al. 2013; Jacob et al. 2014; Kotlarski et al. 2014). In an attempt to highlight the need of using higher resolutions to study the RCM added value, few weather phenomena over North America are evaluated here using RCM hindcast simulations at $0.44^{\circ}, 0.22^{\circ}$ and $0.11^{\circ}$ driven by the ERA-Interim reanalysis.

The added value of RCMs simulations is associated to their enhanced horizontal resolution, which implies three main potential advantages compared to lower resolution GCMs (e.g., Di Luca et al. 2012). First, the finer resolution allows a more realistic representation of surface forcings such as orography, lakes, rivers and coastal regions. Second, the finer resolution allows a more accurate discretization of equations, and thus, a better simulation of the atmospheric circulation and gradients. Third, with finer resolution, a broader range of fine-spatial scale processes can be explicitly resolved; this includes mesoscale weather phenomena such as sea breezes, lake-effect snowstorms, local winds, tropical cyclones and mesoscale convective systems. Consequently, RCMs' added value is mainly expected in the simulation of topography-influenced phenomena and extremes that have relatively small spatial or short temporal character (Flato et al. 2013). Recognizing that the variance of most atmospheric fields is dominated by large scales, several RCM added value studies have used horizontal scale decomposition to isolate the fine scales where added value is most expected (e.g., Feser et al. 2006; Di Luca et al. 2012). This approach however has its limitations as even local weather phenomena occur as a consequence of the superposition and interactions of a wide range of scales. Moreover, the low availability of good quality high-resolution homogeneous observation networks challenges the evaluation of simulated RCM added value with observed features (Leung et al. 2003; Lucas-Picher et al. 2012). Recently, improved coordination between organizations allowed the emergence of interesting observationally-based high-resolution gridded datasets, such as E-OBS (Haylock et al. 2008), USA1/16 (Livneh et al. 2013), STAGE IV (Lin and Mitchell 2005), APHRODITE (Yatagai et al. 2012), SAFRAN (Vidal et al. 2010), which could be better exploited to identify added value.

Among the studies using RCMs, the added value feature that is the most often reported is the one associated to the orographic forcing that is improved at high resolution due to higher mountains and deeper valleys. Leung and Qian (2003) revealed that along the Cascades and the Sierra Nevada range, winter precipitation in their $13-\mathrm{km}$ RCM simulation is strongly amplified compared to another 40-km RCM simulation. This amplification improves the spatial distribution of precipitation and yields a higher spatial correlation between simulations and observations. They also found that increased precipitation is mainly associated with more frequent heavy precipitation at finer resolution. In the same vein, but over Florida with its rather flat terrain, Stefanova et al. (2012) showed that high-resolution RCM simulations reduced the wet bias, provided a more realistic spatial distribution and gave a better diurnal cycle of summer precipitation compared to the driving reanalyses. They attributed the better simulation of seasonal precipitation to the more accurate representation of spatial and temporal structure of finer-scale phenomena such as fronts and sea breezes in the RCM.

Leung and Qian (2003) mentioned that more improvements could be expected from the use of higher spatial resolutions on snowpack than precipitation because snowpack depends also on temperature, which can be much improved with a better representation of the terrain elevation. Using an RCM at different resolutions, Rasmussen et al. (2011) showed that annual snowfall over the Colorado Headwaters regions is in good agreement with observations when horizontal grid spacing of $6 \mathrm{~km}$ or finer is used. In an intercomparison of RCMs over North America, Salzmann and Mearns (2012) showed that RCMs are able to improve significantly the annual snow cycle compared to the unrealistic low values of snow water equivalent depicted by NCEP-NCAR reanalysis. Also, Klehmet et al. (2013) revealed that a 50-km RCM can improve snow water equivalent estimations compared to the forcing NCEP reanalysis over Siberia.

Another feature that can show added value in RCM simulation is the wind intensity and direction in coastal regions. Herrmann et al. (2011) noted that dynamical downscaling significantly reduces the reanalyses underestimation of daily wind speed over the whole Mediterranean. They revealed that added value of the high-resolution simulations is localized in coastal regions and regions of intense winds submitted to the influence of a mountainous orography. Winterfeldt and Weisse (2009) reached a similar conclusion with two RCMs showing added value for instantaneous wind speeds in European coastal regions such as the English Channel where nearby topography and associated local wind regimes become important. $\mathrm{Li}$ (2016) used satellite and in situ observations to show that a 7-km RCM can add value to its driving reanalysis in reproducing wind intensities and direction, probability distribution and extreme winds over the Bohai Sea and the Yellow Sea. Another example of a regional wind that is improved in RCM simulations is the winter wind induced by orographic channeling along the St. Lawrence River Valley (Roebber and Gyakum 2003; Cholette et al. 2015).

An additional important climatic feature in Southwestern North America that can be improved with RCMs is the 
North American monsoon (NAM) where a large fraction of the annual precipitation falls from July to August (Bukovsky et al. 2013). The NAM depends on the near-surface onshore flow into northwest Mexico and Arizona, and the northward low-level jet along the Gulf of California (GOC) that transports the moisture necessary for precipitation (Douglas et al. 1998; Bukovsky et al. 2013). These features and the topography are not well resolved in GCMs (Collier and Zhan 2007). Bukovsky et al. (2013) revealed that 50-km RCMs can reproduce the monsoon system and simulate a spatial distribution of precipitation that is superior to that of the GCMs, given the better-defined orography and coastal features of the GOC and Baja California Peninsula at finer resolution.

The COordinated Regional Downscaling EXperiment (CORDEX) is an initiative from the World Climate Research Program (WCRP) to conduct specific regional climate models simulations to serve the impact and adaptation community and to facilitate the intercomparison studies (Giorgi et al. 2009). In the CORDEX framework, climate-modelling centres around the world are invited to perform RCM simulations over predefined large continental domains. The horizontal resolution of the simulations is fixed to a relatively coarse grid mesh of $0.44^{\circ}$ in order to give the opportunity to centres with less computer power to participate to the project and to generate large ensembles of simulations. Centres with stronger computing resources are invited to perform finer resolution simulations to investigate the added value. However, due to the large CORDEX domains, only few groups can afford resolutions higher than $0.44^{\circ}$.

This paper addresses the need of higher resolution simulations to quanitfy the RCM added value by exploiting recent observationally-based gridded datasets. In this work, three hindcast simulations performed with the fifth-generation Canadian Regional Climate Model (CRCM5) using grid meshes of $0.44^{\circ}, 0.22^{\circ}$ and $0.11^{\circ}$ will be compared. The analysis focuses on the evaluation of several weather phenomena that exhibit added value by comparing the RCM simulations between themselves, their driving reanalysis field, and different gridded observations or individual weather stations. The use of the same model and domain at different resolutions allows identifying clearly weather phenomena that are better simulated at finer resolutions. The following analysis takes advantage of the RCM simulations that cover the entire North American continent to explore weather phenomena in different climatic zones (Fig. 1).

The next section describes the regional climate model that has been used and the details of the simulations. In Sect. 3, the basic climatology of the simulations is evaluated with gridded observations. Section 4 presents different weather phenomena showing added value at finer

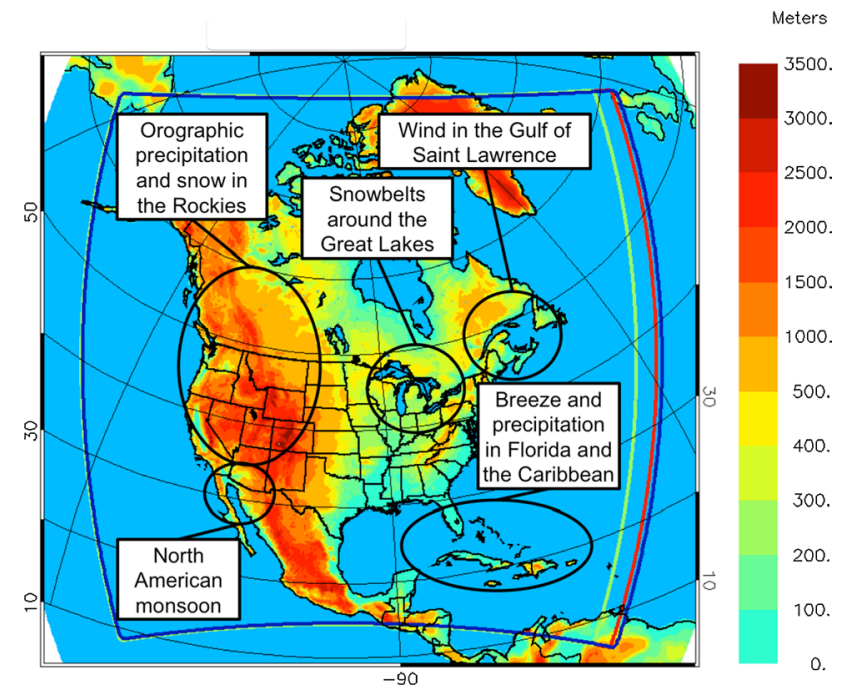

Fig. 1 Orography (m) of North America of the $0.11^{\circ}$ CRCM5 simulation (colours). The free domains of the three CRCM5 simulations are indicated in blue $\left(0.44^{\circ}\right)$, red $\left(0.22^{\circ}\right)$ and green $\left(0.11^{\circ}\right)$. Also indicated, overview of the weather phenomena and regions where the added value is investigated

resolutions. General conclusions and final remarks are reported in Sect. 5.

\section{Description of the CRCM5 and the simulations}

The RCM used in this study is the fifth-generation of the Canadian Regional Climate Model (CRCM5) (Martynov et al. 2013; Šeparović et al. 2013) developed at the Centre pour l'Étude et la Simulation du Climat à l'Échelle Régionale (ESCER) at the Université du Québec à Montréal (UQAM). The CRCM5 is based on a limited-area version of the Global Environment Multiscale (GEM) model used for Numerical Weather Prediction at Environment Canada (Côté et al. 1998). GEM employs semi-Lagrangian transport and (quasi) fully implicit marching scheme. The physical parameterization of the CRCM5 is mostly based on the 33-km meso-global GEM model (Bélair et al. 2005, 2009) employed for numerical weather prediction at the Canadian Meteorological Centre (CMC). Two distinct elements however have been implemented in CRCM5. The Canadian land-surface scheme CLASS (Verseghy 2009) version 3.5, allowing a flexible number of layers and depth, is used in the CRCM5, and lakes are represented by the 1-D FLake model (Martynov et al. 2012). The CRCM5 has contributed to the CORDEX project over North America (Martynov et al. 2013; Šeparović et al. 2013), Africa (Hernández-Díaz et al. 2013; Laprise et al. 2013), South Asia (Alexandru and Sushama 2015), and work is in progress for the Arctic (Takhsha et al. 2016). The detailed description of the 
CRCM5 model and its performance over North America with a grid mesh of $0.44^{\circ}$ can be found in Martynov et al. (2013).

Three simulations were performed from 1979 to 2014 with horizontal grid meshes of $0.44^{\circ}, 0.22^{\circ}$ and $0.11^{\circ}$ on rotated latitude-longitude coordinates. The hindcast simulations were driven at their lateral boundaries by the ERA-Interim reanalysis (Dee et al. 2011) on a grid mesh of $0.75^{\circ}$. The ERA-Interim fields that forced the RCM at the atmospheric lateral boundaries are the horizontal wind components, the temperature, the specific humidity and the surface pressure. These variables are available at $6 \mathrm{~h}$ intervals and a linear temporal interpolation is used to provide data to the RCM at every time step. The free domains of these simulations respect the minimum North American CORDEX requirements. All the domains have the exact same lateral boundaries' locations, except for the eastern boundary where the location changes a little to respect the fast Fourier transform criteria on the number of grid cells in the domain (Fig. 1). The $0.44^{\circ}, 0.22^{\circ}$ and $0.11^{\circ}$ domains contain respectively $192 \times 180,360 \times 340$ and $675 \times 660$ grid cells in the $\mathrm{x}$ and $\mathrm{y}$ directions, including a nudging zone of 10 grid cells around the domain perimeter. No large-scale spectral nudging was applied in the domain interior for these simulations. Sea surface temperature and sea-ice fraction from ERA-Interim are prescribed once per day. All simulations use 56 levels in the vertical and the same subgrid-scale physical parameterization; only the time step was shortened with increasing resolution (20 min at $0.44^{\circ}, 10 \mathrm{~min}$ at $0.22^{\circ}$ and $5 \mathrm{~min}$ at $0.11^{\circ}$ ). With smaller time steps and an increased number of grid cells in the $\mathrm{x}$ and $y$ directions, the $0.22^{\circ}$ and the $0.11^{\circ}$ simulations are respectively around 8 and 64 times more expensive in computer resources than the $0.44^{\circ}$ simulation.

\section{Evaluation of the long-term climatology of the CRCM5 hindcast simulations}

Throughout the analysis, different observational datasets detailed in Table 1 are used to evaluate the added value in the CRCM5 climate simulations. With different projections and horizontal grid spacings, the exploration of different observational datasets is challenging. In order to preserve spatial details where added value could be present, one method consists in presenting the observational and model datasets on their native grid. This method has the advantage of highlighting RCM fine scales; the resolution mismatch however may result in more extreme values appearing in the finer mesh dataset than the coarser one. An alternative method, consisting in the aggregation of the observational datasets and CRCM5 simulations to a common (generally coarser) grid, can solve the resolution mismatch, but some of the added value associated with finer scale weather phenomena such as orographic precipitation or lake effect risks being filtered. Since the main goal of this paper is to identify RCM added value and highlight the weather phenomenon causing it, the first option where datasets are presented on their native grid was selected; fields were only interpolated when computations such as differences between two datasets were required.

Before paying close attention to the weather phenomena showing added value (Fig. 1), Figs. 2 and 3 show the 2-m air temperature and precipitation biases of the long-term climatology of the CRCM5 simulations and ERAI with respect to the $0.5^{\circ}$ monthly CRU gridded analysis of observations (Harris et al. 2014). In winter, the three CRCM5 simulations exhibit a similar cold bias (Fig. 2), down to $-2{ }^{\circ} \mathrm{C}$, over most of North America, except over the Rocky Mountains where the cold bias is larger. Over Ontario and southern Québec, however, the CRCM5 simulations exhibit a warm bias, up to $+2{ }^{\circ} \mathrm{C}$, which coincides with the location of the boreal forest that is likely too dense, affecting the snow cover, and thus the albedo over the canopy in the land-surface scheme.

In summer, the three CRCM5 simulations are warmer (up to $+2{ }^{\circ} \mathrm{C}$ ) than $\mathrm{CRU}$ over the United States and most of Canada (Fig. 2). As for winter, there is a cold bias over mountainous Mexico down to $-5{ }^{\circ} \mathrm{C}$. In order to evaluate the robustness of the CRU dataset that is used as a reference, CRU is also compared with the ERA-Interim reanalysis (ERAI), which is used as boundary conditions for the CRCM5 simulations, and a merged observationally-based gridded dataset (hereafter NAOBS). NAOBS combines the $0.125^{\circ}$ dataset of Maurer et al. (2002) covering the contiguous USA and the $10-\mathrm{km}$ Gridded Climate Dataset for Canada (GCDC), provided by the National Land and Water Information Service of Canada (Hutchinson et al. 2009). The bias of ERAI and NAOBS with respect to CRU is limited to $\pm 1{ }^{\circ} \mathrm{C}$ in summer and winter, except over the Arctic, the Rocky Mountains and Greenland where few weather stations are located. The small 2-m air temperature difference of ERAI and NAOBS increases the trust in the CRU dataset used as a reference.

For precipitation (Fig. 3), the relative biases of the CRCM5 simulations at different resolutions with respect to CRU in winter are again similar and mainly within $25 \%$ over southern Canada. Over the United States, the CRCM5 simulations are slightly wetter than CRU in winter, except over the prairies and the Arctic where the wet relative bias is amplified due to the dry conditions in these regions. In summer, the precipitation bias is small and similar between the CRCM5 simulations, except over Florida that is wetter at finer resolutions. Also, the dry bias is smaller at finer resolutions over southwestern United States where the North American monsoon takes place. The weather phenomena 


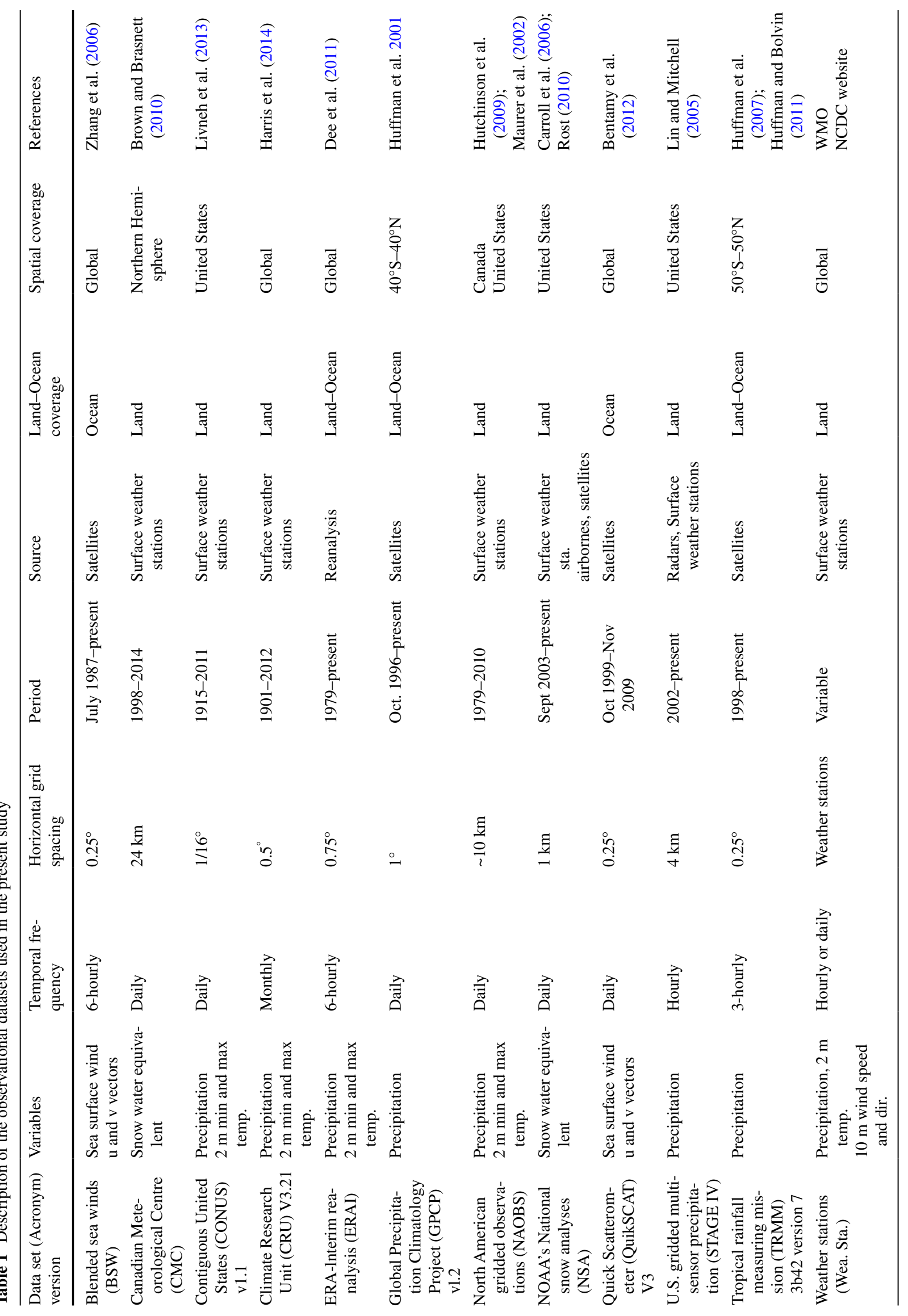


Fig. 2 1981-2010 DJF and JJA 2-m air temperature bias $\left({ }^{\circ} \mathrm{C}\right)$ of the CRCM5 simulations, and ERAI and NAOBS datasets with respect to CRU. The CRU maps show the mean 1981-2010 DJF and JJA 2-m air temperature $\left({ }^{\circ} \mathrm{C}\right)$. For calculating the biases, CRU data was regridded to the CRCM5, ERAI and NAOBS grids

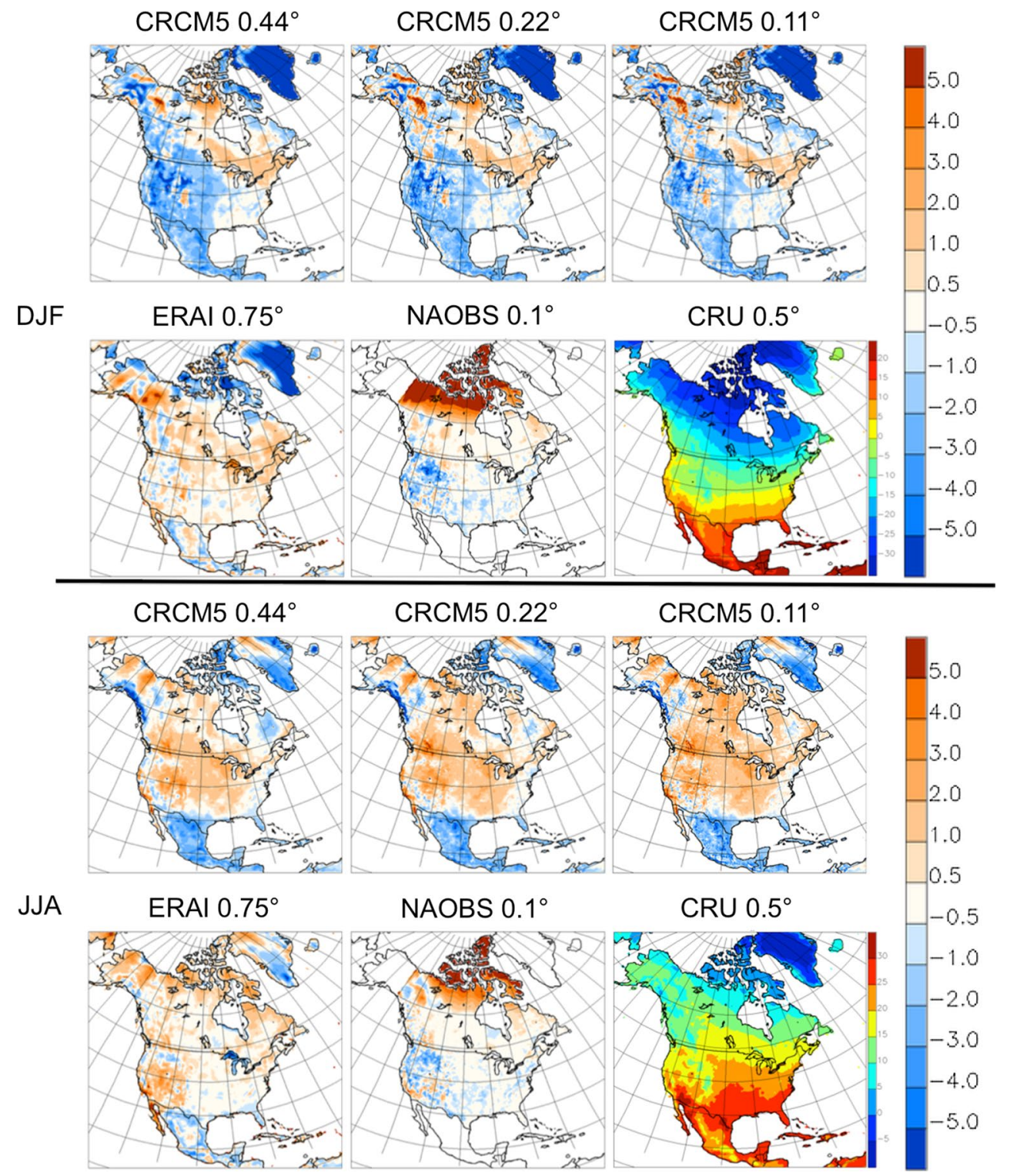

that produce precipitation over the latter two regions will be studied thoroughly in the next section. For both seasons, precipitation from NAOBS is very similar to CRU, except in the Rocky Mountains in winter and over northern Canada where gridded observations are unreliable due to the small density of weather stations. As for the CRCM5 simulations, ERAI is too wet in southeastern United States and too dry in southwestern United Stated in summer. Overall, the CRCM5 long-term climatology shows a satisfactory performance at different horizontal resolutions and seems to be little affected by the reduction of the time steps with increasing resolutions. On the other hand, little improvement (or added value) is found at the large scales at finer resolutions using multi-year seasonal means.

\section{Weather phenomena showing added value at finer resolutions}

In this section, different weather phenomena (Fig. 1) simulated by the CRCM5 at different resolutions will be compared to ERAI and different observed datasets to identify evidence of RCM added value at increasing resolutions.

\subsection{Orographic precipitation and snow in the Rocky Mountains}

Orographic precipitation is generated when a moist air mass, pushed by the winds, is forced to move up a high mountain. The lift of the air up the side of the mountain 
Fig. 3 1981-2010 DJF and JJA relative precipitation bias of the CRCM5 simulations, and ERAI and NAOBS datasets with respect to CRU. The CRU maps show the mean 1981-2010 DJF and JJA precipitation $(\mathrm{mm} /$ day). For calculating the biases, CRU data was regridded to the CRCM5, ERAI and NAOBS grids

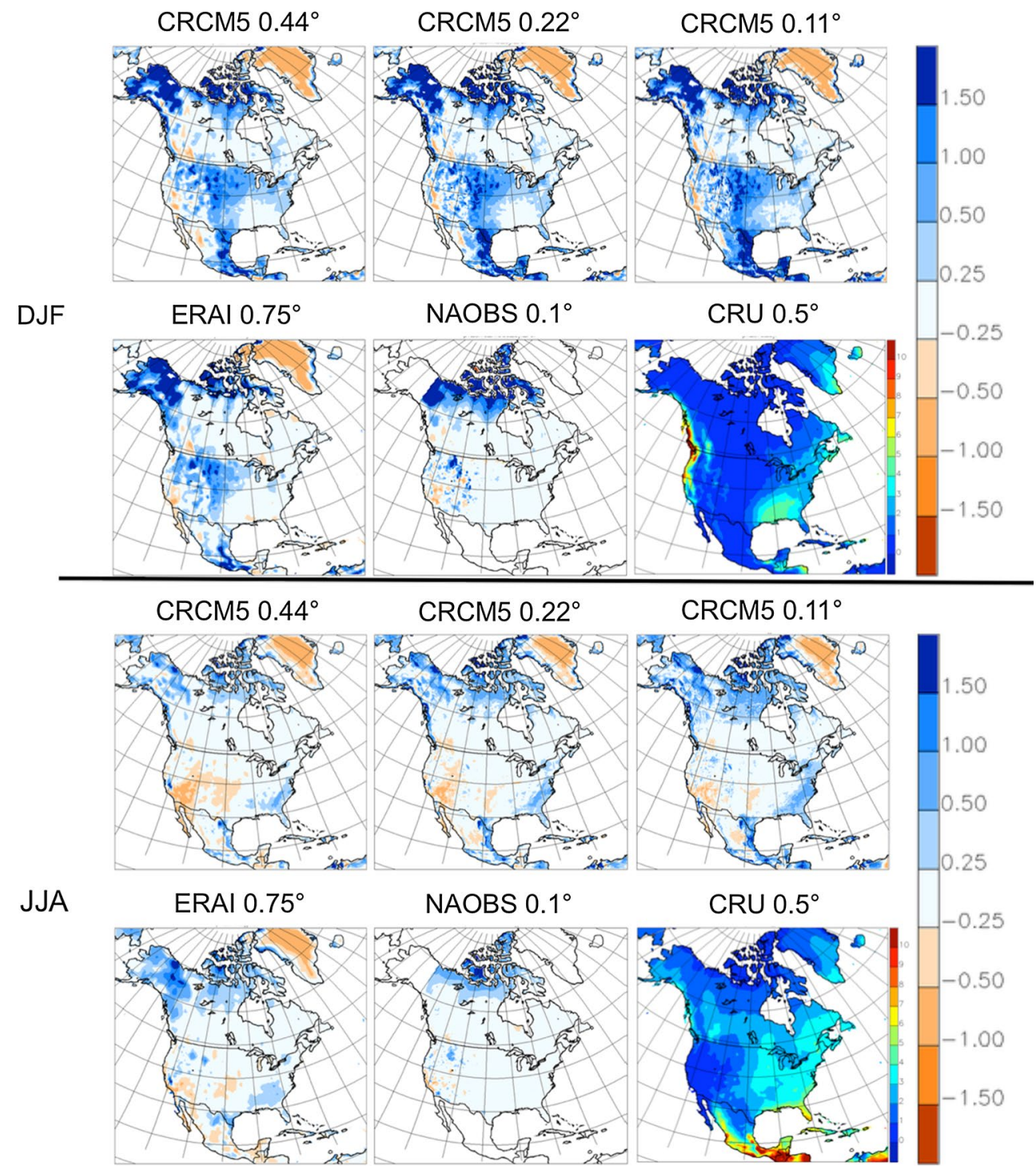

results in adiabatic cooling, which leads to an excess of water vapour that condenses to form cloud droplets, and ultimately generates precipitation. Thus, the windward side of a mountain affected by prevailing winds is usually wetter and the leeward side of the mountain is usually dryer due to the moisture released when precipitation occurs. Orographic precipitation is an important phenomenon that affects a large portion of the west coast of North America. Indeed, the winter prevailing westerly winds from the Pacific Ocean hit the Pacific Coast Ranges, generating precipitation in the Vancouver region of Canada and the Seattle region of the United States that are known as some of the rainiest regions of North America.

Due to their coarse horizontal resolutions, GCMs and reanalyses have smooth orographies with low mountains and shallow valleys. Thus, with lower mountains, the orographic precipitation from GCMs and reanalyses is generally underestimated, as shown by the 1981-2010 DJF precipitation on the west coast of North America for ERAI (Fig. 4). On the other hand, the west coast orographic precipitation of the CRCM5 simulations is enhanced compared to ERAI and closer to the CRU and NAOBS gridded datasets. The enhanced CRCM5 orographic precipitation is a consequence of the higher, sharper and more realistic mountains of the CRCM5 simulations due to their finer resolutions (see the cross section in Fig. 5a). For the cross sections of Fig. 5a, b, one of the highest resolution gridded observations over the United States, the $1 / 16^{\circ}$ grid spacing CONUS (Livneh et al. 2013), is used as the observational reference. In Fig. 5, the precipitation of CRU on the west coast is lower than that of NAOBS, likely because CRU is on a coarser mesh and uses fewer weather stations compared to NAOBS. Moreover, gridded estimates of observed precipitation are generally underestimated because weather stations are mainly located in the valleys that are dryer and due to the snowfall undercatch in winter. ERAI, CRCM5 
Fig. 4 1981-2010 DJF precipitation (mm/day) over western North America. The horizontal black line on the CRCM5 $0.11^{\circ}$ map indicates the cross section presented in Fig. 5
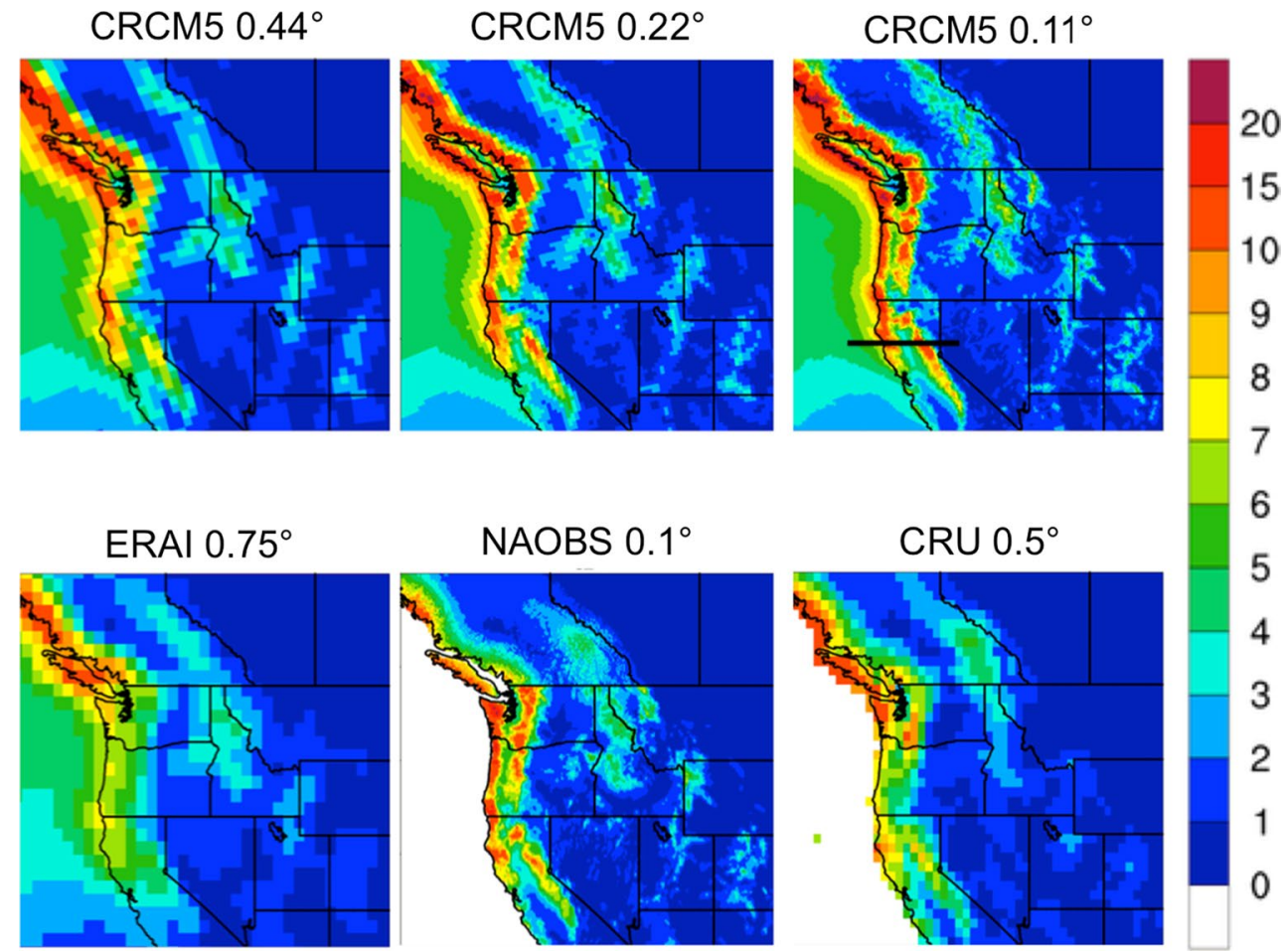

at $0.44^{\circ}$ and $\mathrm{CRU}$ are comparable and have only one rain band due their smooth mountains at coarse resolutions. With finer resolutions, CRCM5 simulations at $0.22^{\circ}$ and $0.11^{\circ}$ are similar to NAOBS with two rain bands: one on the windward side of the Pacific Coast Ranges, and a second one on the windward side of the Sierra Nevada and the Cascade Range (Figs. 4, 5).

With higher mountains at increasing horizontal resolutions, not only the orographic precipitation is enhanced, but also the 2-m air winter temperature is colder and more realistic (Fig. 5b). As a consequence, with more precipitation and colder conditions, higher amounts of snow are simulated and remain on the mountains peaks at finer resolutions (Fig. 5c). In Figs. 5c and 6, the observational reference of snow water equivalent (SWE) is the 1-km National Snow Analysis (NSA), available since 2003 from the National Oceanic and Atmospheric Administration (NOAA; Carroll et al. 2006; Rost 2010). In Fig. 6 showing a climatology of SWE in February, CRCM5 $0.11^{\circ}$ has more snow than CRCM5 $0.22^{\circ}$ and CRCM5 $0.44^{\circ}$ over the Rocky Mountains, the Sierra Nevada and the Cascades. CRCM5 0.11 ${ }^{\circ}$ is also closer than the other CRCM5 simulations to NSA. With smoother mountains than the CRCM5 simulations, the ERAI fields are drier and warmer (Fig. 5a, b), leading to lower values of SWE (Figs. 5c, 6). In Fig. 6, another snow analysis from the Canadian Meteorological Centre (CMC) (Brown et al. 2003; Brown and Brasnett 2010) shows smaller values of SWE than NSA, likely as a consequence of smoother mountains at a grid spacing of $24 \mathrm{~km}$, snowfall undercatch and weather stations located mainly in the drier valleys. In summary, finer resolution RCM simulations show distinct added value with improved orographic precipitation and snow amounts due to higher and sharper mountains in western North America.

\subsection{North American monsoon}

The North American monsoon (NAM) is a weather phenomenon that produces a pronounced rainfall increase during a sharp transition from a dry June to a rainy July over large areas of southwestern United States and northwestern Mexico. Bukovsky et al. (2013) highlighted that the near-surface onshore flow into northwest Mexico and Arizona, the northward low-level jet along the Gulf of California, together with the topography, as crucial ingredients for a realistic simulation of the NAM, none of which are well resolved by most GCMs participating in century time-scale climate-change projections. These authors also revealed that these features are improved in RCMs simulations, but that the $50-\mathrm{km}$ mesh of their RCM ensemble may be too coarse to resolve all of the necessary terrain, coastline, and mesoscale circulation features in this region. Figure 7 showing the CRCM5 1981-2010 August precipitation confirms the last statement. Indeed, the spatial distribution of CRCM5 $0.11^{\circ}$ is closer to CONUS than CRCM5 $0.22^{\circ}$ and $0.44^{\circ}$. One of the most notable improvement at finer resolutions is the fine-scale precipitation details over Colorado, and especially Utah, that are missing for 

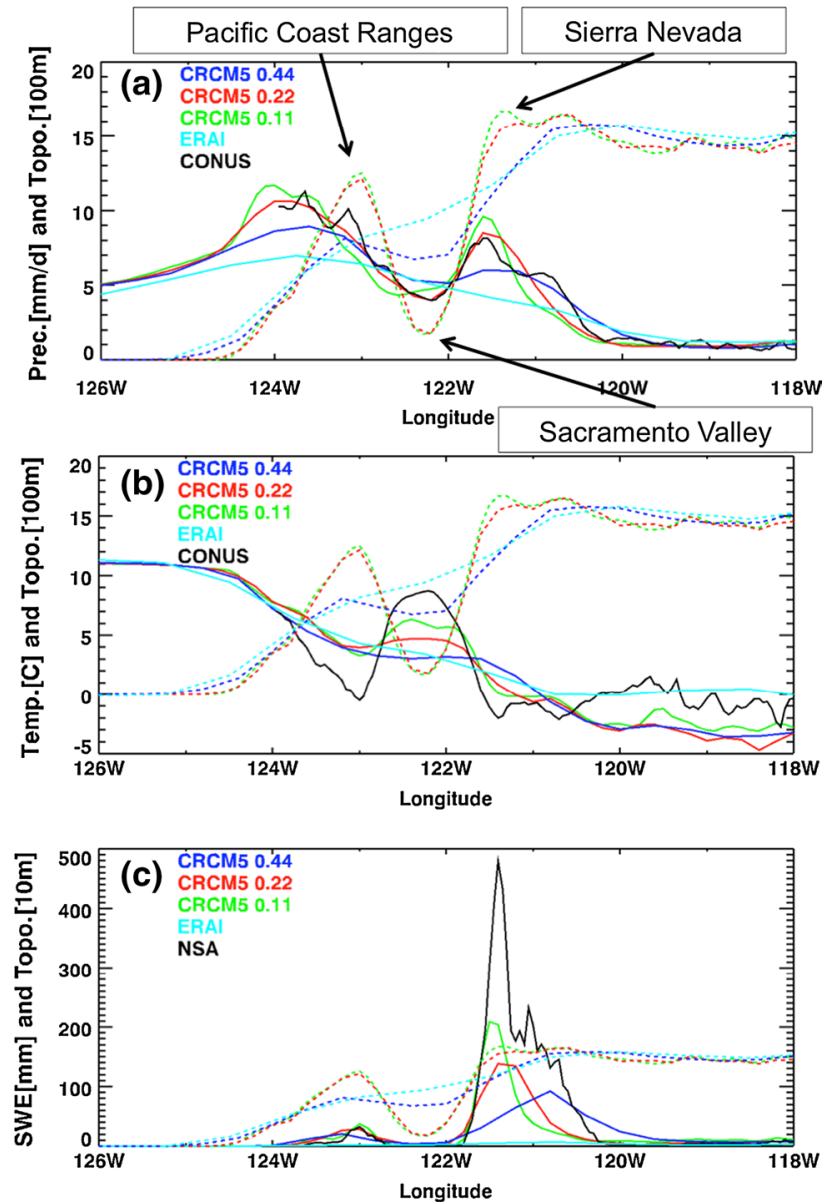

Fig. 5 West to East cross section, averaged between $40 \mathrm{~N}$ and $40.5 \mathrm{~N}$, of the a 1981-2010 DJF precipitation (mm/day), b 19812010 DJF 2-m air temperature $\left({ }^{\circ} \mathrm{C}\right)$, and c 2004-2010 February snow water equivalent $(\mathrm{mm})$. The location of the cross section is indicated in Fig. 4. The full lines indicate the precipitation, 2-m air temperature or snow water equivalent while the dashed lines indicate the orography

CRCM5 $0.44^{\circ}$ and $0.22^{\circ}$, and ERAI, but apparent for CRCM5 $0.11^{\circ}$. These features are likely linked to the more realistic topography and mesoscale atmospheric circulation at $0.11^{\circ}$.

Figure 8 gives an overview of the monsoon season with the annual cycle, diurnal cycle and distribution of precipitation for the same region as Gutzler et al. (2005) covering Arizona and New Mexico (AZNM), and the city of Alpine indicated in Fig. 7. Over AZNM, the increase of precipitation from June to July is better simulated at $0.11^{\circ}$ and $0.22^{\circ}$. However, all CRCM5 simulations and ERAI simulate too little precipitation in July and August. All the CRCM5 simulations have a diurnal cycle close to the 3-hourly $0.25^{\circ}$ TRMM (Huffman et al. 2007), with a maximum at around 20 UTC (13 LST) that is however weaker than observed. ERAI mean diurnal cycle is somewhat shifted with a too early onset of precipitation. Still over the AZNM region, the three CRCM5 simulations underestimate the mediumintensity precipitation $(4-16 \mathrm{~mm} / \mathrm{day})$. The high-intensity precipitation (above $32 \mathrm{~mm} /$ day) seems to be overestimated by the $0.22^{\circ}$ and $0.11^{\circ}$ CRCM5 simulations; but it is also possible that CONUS underestimates daily precipitation intensities due to the smoothing procedure used to obtain a gridded product from individual weather stations. On the other hand, ERAI captures quite well the medium intensity precipitation, but largely underestimates precipitation intensities above $32 \mathrm{~mm} /$ day.

In order to have a better idea of the quality of CONUS in this region of southwestern United States that is characterized by a sparse distribution of weather stations, the last analysis is repeated for the weather station of the city of Alpine, which is located close to the border of Arizona and New Mexico where the precipitation is large in August (Fig. 7). For the mean annual cycle, CRCM5 $0.11^{\circ}$ simulates more precipitation than CRCM5 $0.22^{\circ}$ and $0.44^{\circ}$ in August and is closer to the value at the weather station that is dryer than CONUS on an annual average. The diurnal cycle seems slightly improved at $0.11^{\circ}$ and $0.22^{\circ}$ over Alpine, but the amount of precipitation between 20 and 4 UTC is still underestimated by the CRCM5 simulations. ERAI mean diurnal cycle is still shifted with a too early rise of precipitation and a smaller diurnal maximum than the CRCM5 simulations. As anticipated, higher precipitation intensities (above $128 \mathrm{~mm} /$ day) were measured at the Alpine weather station compared to CONUS. Only CRCM5 $0.11^{\circ}$ was able to simulate similar high precipitation intensities as the one captured by the Alpine weather station, but all the CRCM5 simulations and ERAI underestimate medium intensities.

Figure 9 illustrates the latitudinal progression of the precipitation intensity between $32^{\circ} \mathrm{N}$ and $40^{\circ} \mathrm{N}$ using a Hovmöller diagram, for a zonal average between $106^{\circ} \mathrm{W}$ and $111^{\circ} \mathrm{W}$. To get a smooth progression, the variability with periods shorter than 12 days was suppressed with a lowpass filter. The North American monsoon is clearly visible on the Hovmöller diagrams, with maximum values of precipitation occurring in July, August and September. Even though CRCM5 $0.22^{\circ}$, and even more $0.11^{\circ}$, seems to occasionally overestimate precipitation compared to CONUS, they seem superior to CRCM5 $0.44^{\circ}$, with a more realistic progression of the monsoon North of $38^{\circ} \mathrm{N}$ in late July and September. Also, CRCM5 $0.22^{\circ}$ and $0.11^{\circ}$ simulations have a longer monsoon season, lasting until early October between $32^{\circ} \mathrm{N}$ and $34^{\circ} \mathrm{N}$, and between $36^{\circ} \mathrm{N}$ and $38^{\circ} \mathrm{N}$. The Hovmöller diagram of ERAI is rather similar to CONUS and TRMM during the monsoon season, but shows more precipitation in March, April and May between $37^{\circ} \mathrm{N}$ and $40^{\circ} \mathrm{N}$. The Hovmöller diagram of TRMM is similar, but smoother than that of CONUS due to a coarser grid spacing of $0.25^{\circ}$ for TRMM compared to $0.06^{\circ}$ for CONUS. 
Fig. 6 2004-2010 February snow water equivalent $(\mathrm{mm})$ over western North America
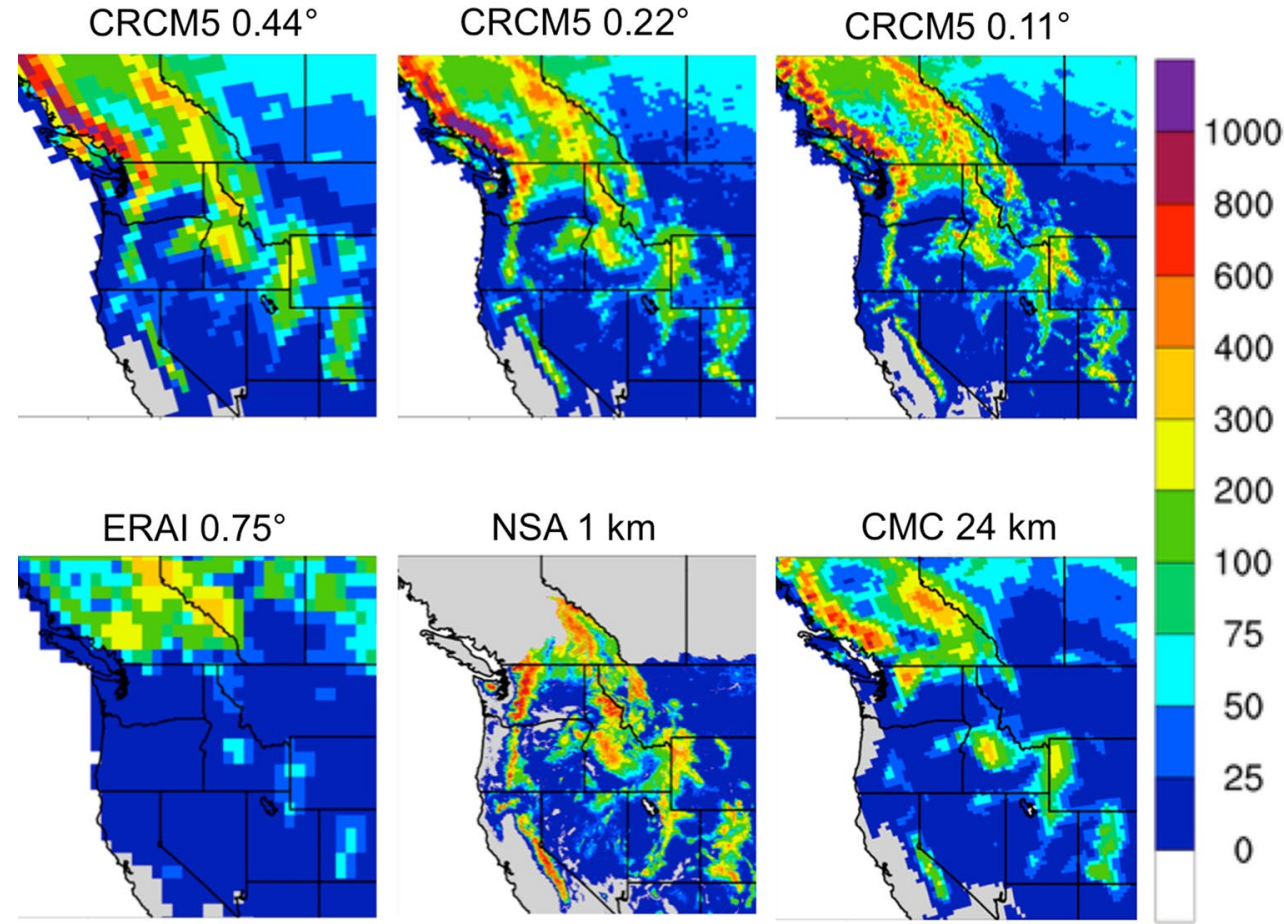

200

100

75

50

25
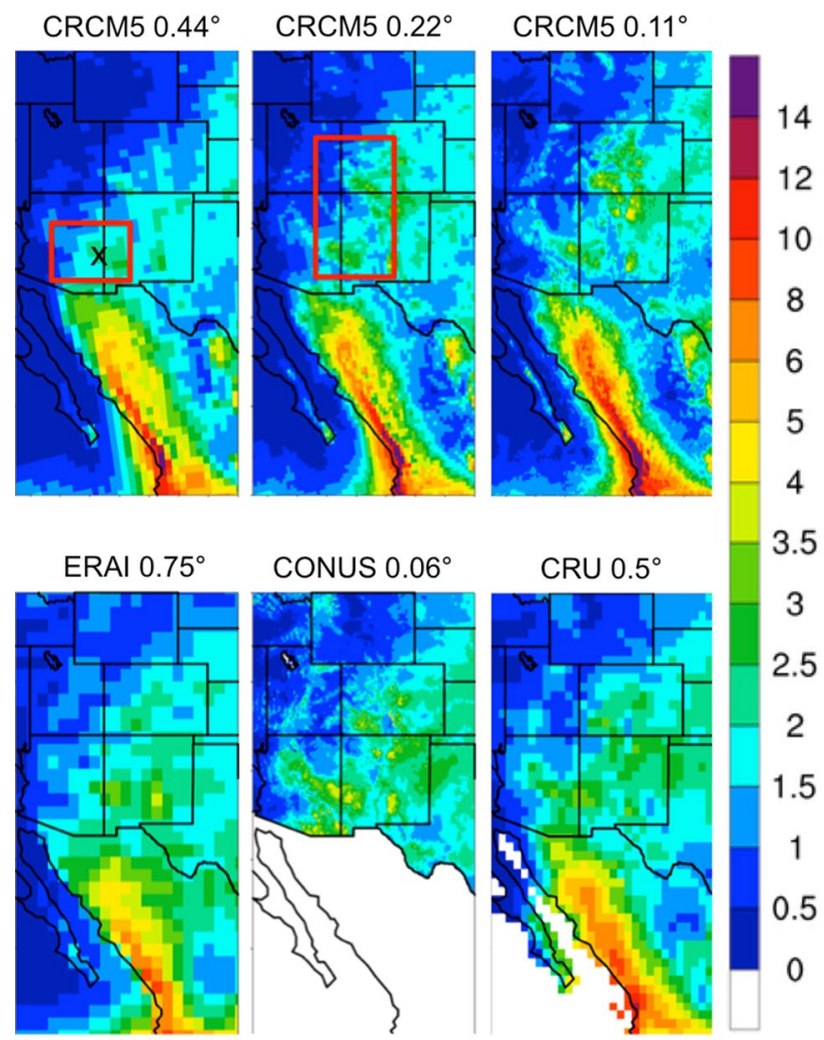

Fig. 7 1981-2010 August precipitation (mm/day) over southwestern United States and northern Mexico. The region AZNM with a red rectangle and the city of Alpine indicated with an $\mathrm{x}$ on the CRCM5 $0.44^{\circ}$ map will be used for the annual and diurnal cycles, and distributions presented in the next figure. The red rectangle on the CRCM5 $0.22^{\circ}$ map will be used for the Hovmöller diagram in Fig. 9
Moreover, with a temporal coverage from 1998 to 2010 only for TRMM, it is difficult to determine if differences between TRMM and CONUS are due to a different time period or to systematic differences. In summary, the NAM is improved in the higher resolution CRCM5 simulation, with added value in the diurnal cycle, distribution of precipitation intensities and spatial distribution, likely because of the more realistic mesoscale atmospheric circulation and topography.

\subsection{Snowbelts around the Great Lakes}

Lake-effect snowfall is produced when a cold and dry continental air mass moves across a large unfrozen lake, warming and moistening the lower layer of air. Thus, this warm moist air rises up through the colder air above, freezes and then produces snow on the downwind shores. Consequently, narrow bands with huge amounts of snow build up giving rise to the snowbelts. Wright et al. (2013) emphasizes that fine-resolution simulations are necessary to correctly reproduce important local-scale interactions that determine the location and intensity of large-effect snow and, as a result, the spatial distribution of snowbelts around the Great Lakes. The important factors that can improve the simulation of snowbelts at higher resolutions are the more precise lake delimitations, sharper surrounding orography and better ability to produce convective systems over the small lakes. In CRCM5, the lake temperature and ice cover are simulated with the 1-D thermodynamic model FLake. This lake model likely gives better lake temperature 

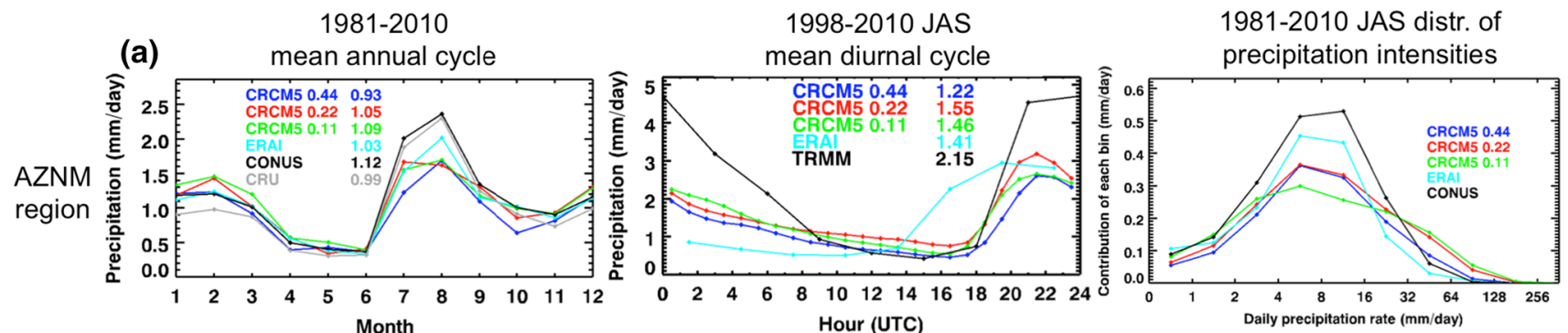

(b)
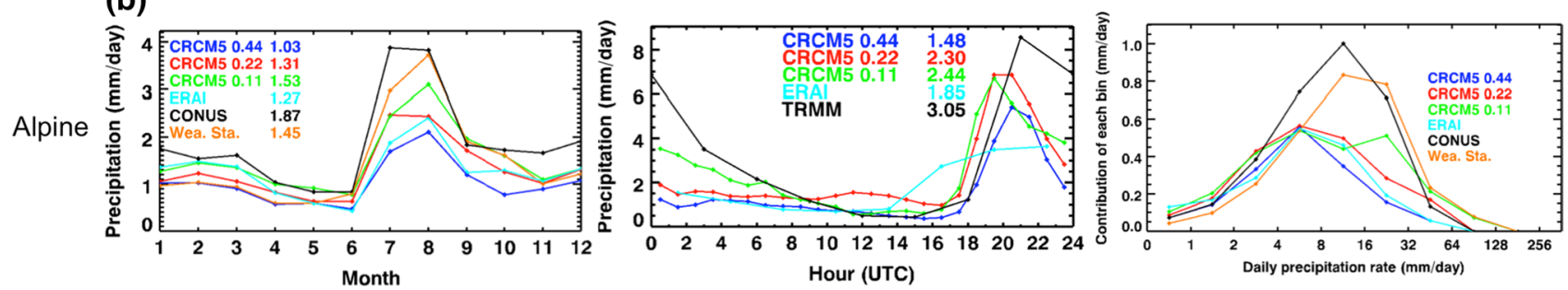

Fig. 8 Mean annual cycle, mean diurnal cycle and distribution of precipitation intensities over a the AZNM region and $\mathbf{b}$ the city of Alpine. The numbers next to the data sources for the mean annual cycle and the mean diurnal cycle correspond to the annual mean and daily mean, respectively. For the city of Alpine, the values of the clos- est grid cell of the CRCM5 simulations, ERAI, TRMM and CONUS to the city, and from the weather station (Wea. Sta.) of the city are displayed. CRCM5 hourly, and TRMM and ERAI 3-hourly cumulative precipitation values are plotted on the central time period over which precipitation is accumulated

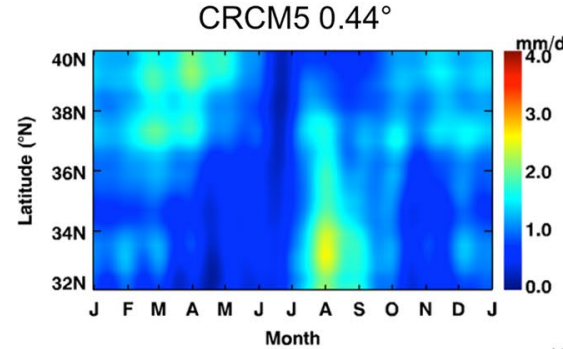

ERAI $0.75^{\circ}$

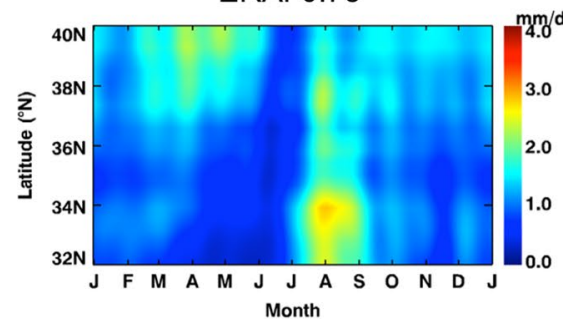

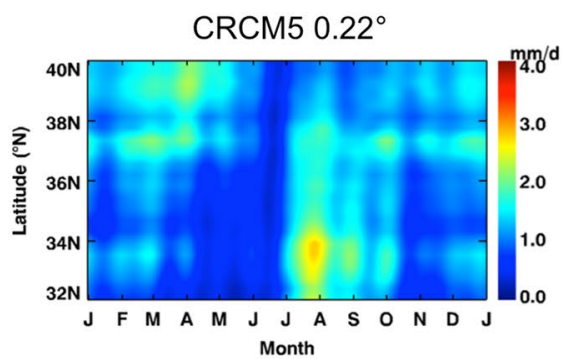

CONUS $0.06^{\circ}$

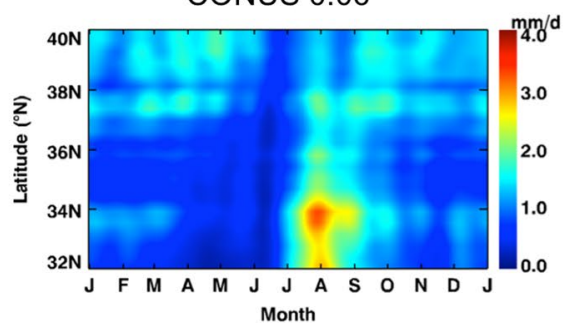

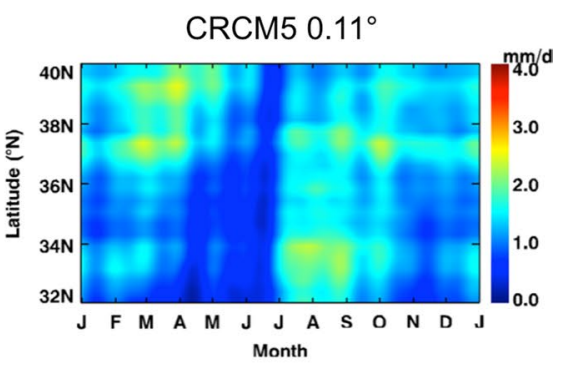

TRMM $0.25^{\circ}(1998-2010)$

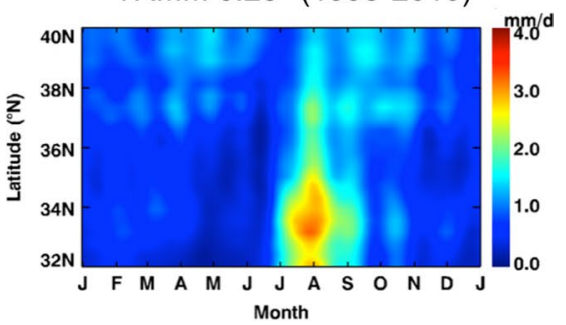

Fig. 9 Hovmöller diagram of the precipitation $(\mathrm{mm} /$ day) for the period 1981-2010 (1998-2010 for TRMM) and for the latitude band $32^{\circ} \mathrm{N}-40^{\circ} \mathrm{N}$. The data has been low-pass filtered to retain only periods longer than 12 days and averaged over the longitude band $106^{\circ} \mathrm{W}-111^{\circ} \mathrm{W}$ as indicated in Fig. 7

the lake and sea-ice extents, the orography and the mesoscale phenomena necessary to reproduce lake-effect snow. At $0.22^{\circ}$, and even more at $0.11^{\circ}$, clear snowbelts appear to the South and East of Lake Superior, to the South of Lake Erie and to the East of Lake Ontario. The snowbelts from CRCM5 $0.22^{\circ}$ and $0.11^{\circ}$ resemble closely those of the snow analysis NSA over the United States. ERAI has an incoherent distribution of snow due to its coarse horizontal horizontal resolution is too coarse to adequately represent 
Fig. 10 2004-2010 February snow water equivalent (mm) over the Great Lakes and Lake Champlain regions
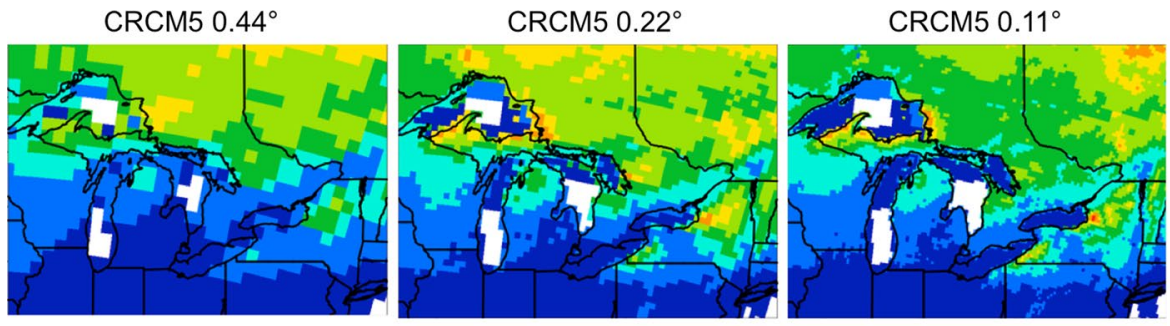

300

200

150

125

ERAI $0.75^{\circ}$

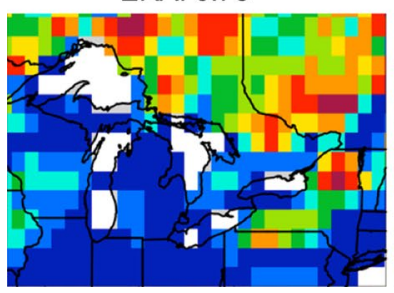

NSA $1 \mathrm{~km}$
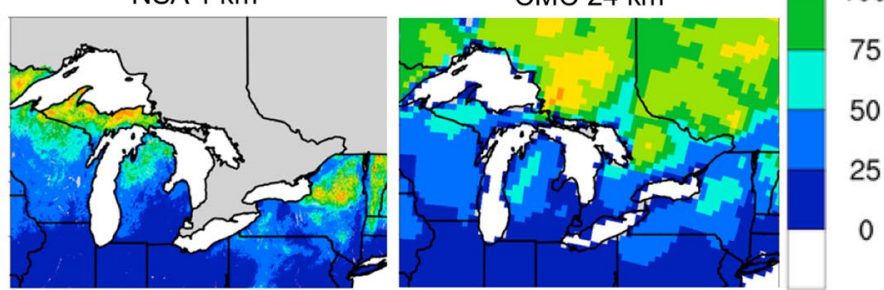

resolution and a geolocation error introduced in the snow analyses from 1 July 2003 to 23 February 2010 (Dee et al. 2011). The CMC SWE offers value over Canada, but is probably limited to the small number of weather stations measuring snow and the relatively coarse $24-\mathrm{km}$ mesh size. Also apparent in Fig. 10 for CRCM5 $0.11^{\circ}$ and NSA only, the low-altitude Lake Champlain Valley has little snow due to its warmer and dryer weather conditions compared to its surroundings that have large snow amounts over the cold and snowy Adirondack and Green Mountains where orographic precipitation takes place (e.g., Lucas-Picher et al. 2015). In summary, the improved representation of the lake delimitations and the orography in the Great Lakes region at finer resolutions allows a better simulation of the smallscale lake-effect snow processes that result in added value snowbelts on the downwind shores of the Great Lakes.

\subsection{Wind in the river valley and Gulf of St. Lawrence}

Due to its great length and its surrounding higher complex orography, the St. Lawrence River Valley (SLRV) is affected by wind channelling that is an important local process, especially in winter. This local feature can produce strong temperature inversions in lower layers of the atmosphere, which, combined with approaching warm front precipitation, can lead to important freezing rain events (Roebber and Gyakum 2003). Cholette et al. (2015) found that, with CRCM5, grid spacing of $27 \mathrm{~km}$ did not allow an adequate simulation of wind channelling in the SLRV, while grid spacing of $9 \mathrm{~km}$ did. Figure 11 shows the 2000-2008 September-October-November (SON) mean and 95th percentile 10-m wind speed in the Gulf of St. Lawrence where significant marine traffic takes place and that is ice-free in fall. Two $0.25^{\circ}$ gridded satellite-based products (QuikSCAT and Blended Sea Winds; BSW) are presented to evaluate wind speed from the CRCM5 simulations and ERAI. We employed the QuikSCAT reprocessed daily wind speed from IFREMER (Bentamy et al. 2012) that is improved in rainy and windy conditions. The 6-hourly BSW (Zhang et al. 2006) was generated by blending multiple satellites (up to six since June 2002) that fill in the data gaps (in both time and space) of the individual satellite samplings.

In Fig. 11, QuikSCAT and BSW are generally in good agreement, though QuikSCAT slightly underestimates the 95th percentile wind speed compared to BSW. At the largescale, the mean and extreme wind speeds from ERAI are close to the two satellite products, but more locally on the coasts and in the SLRV, ERAI underestimates wind speed. The CRCM5 $0.44^{\circ}$ simulation also suffers of local underestimations. The wind speeds from CRCM5 $0.22^{\circ}$ and $0.11^{\circ}$ are faster and closer to the gridded observations in the SLRV, around the Anticosti Island, near the coasts of Nova Scotia, Newfoundland and Maine, and in the Bay of Fundy. With finer resolution, the better-defined coastline and orography modify the surface roughness and local atmospheric circulation, which leads to a more realistic $10-\mathrm{m}$ wind speed. To highlight the local-scale wind speed and direction improvements, Fig. 12a shows the wind roses of the CRCM5 simulations, ERAI and the weather station at Île d'Orléans, located in the SLRV downstream of Québec City. Clearly, with its predominant southwest and northeast wind directions forced along the SLRV axis, the wind rose from the CRCM5 $0.11^{\circ}$ is in better agreement with that of the weather station compared to coarser CRCM5 simulations and ERAI that mainly exhibit the large-scale prevailing westerly winds. Moreover, with the narrowing SLRV from the Gulf towards Québec City, the funnel effect that increases the wind speed is better captured by the finer resolution CRCM5 simulations as shown in the distribution of wind speed intensity in Fig. 12b. Overall, coastal regions with complex orography show added value at finer resolutions with a better simulation of local winds such as the 
Fig. 11 2000-2008 SON a mean and $\mathbf{b} 95$ th percentile $10-\mathrm{m}$ wind speed $(\mathrm{m} / \mathrm{s})$ in the Gulf of St.-Lawrence. The black $\mathrm{x}$ of the BSW map indicates the Île d'Orléans for the wind rose in the next Figure
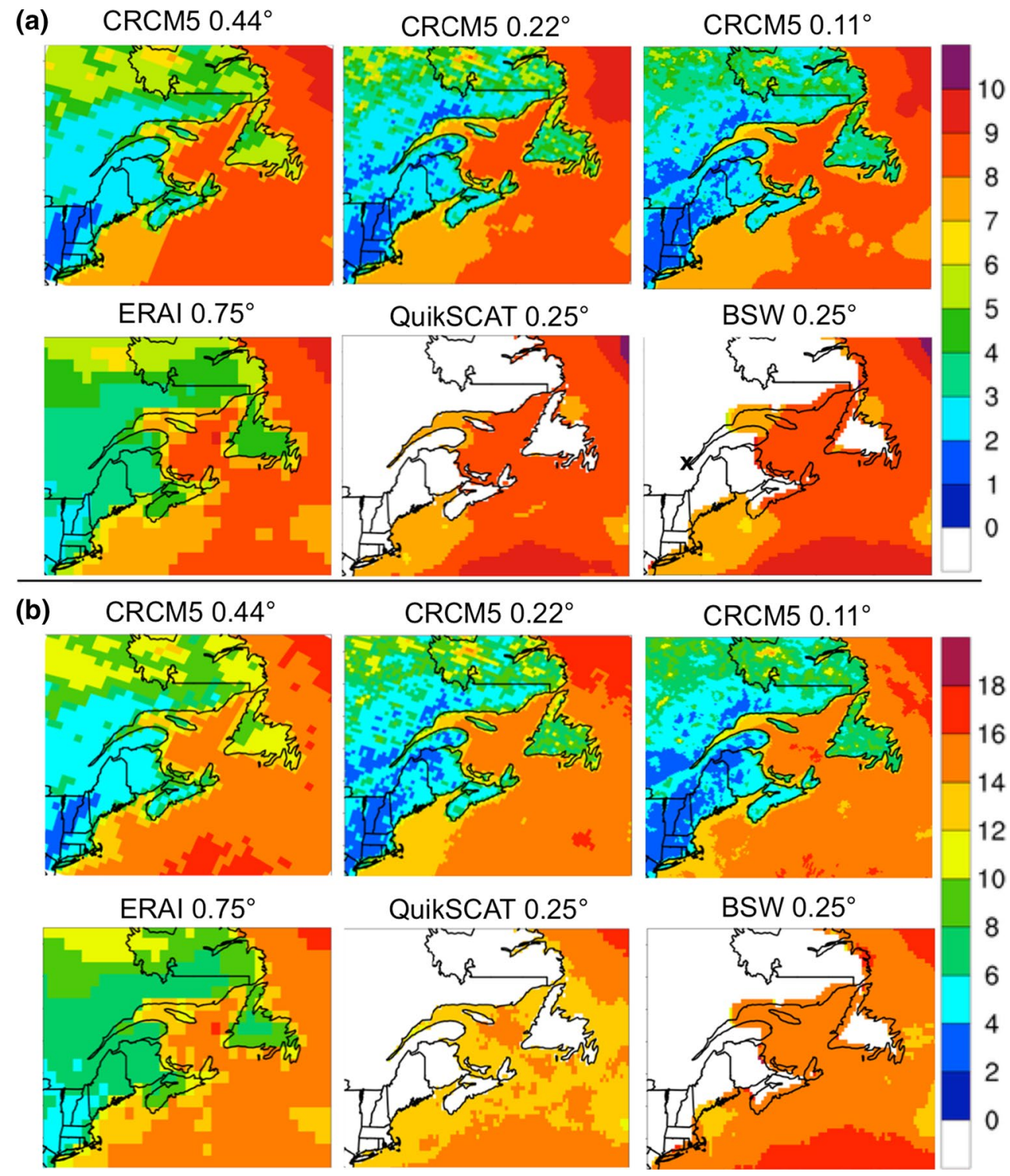

predominant winter southwesterly and northeasterly winds along the SLRV axis.

\subsection{Precipitation over Florida and the Caribbean}

Summer precipitation in southeastern United States is a particularly challenging modeling problem because of the variety of regional-scale phenomena, such as sea breeze, thunderstorms and squall lines, which are not adequately resolved in coarse atmospheric reanalyses (Stefanova et al. 2012). Still in the tropics, but over the Maritime Continent (Indonesia, Philippines and Papua New Guinea), Qian (2008) showed that precipitation is mostly concentrated over islands because of the sea-breeze convergence that is reinforced by mountain-valley winds and further amplified by cumulus merger processes. Both previous studies described the improvements of the mesoscale processes with fine-resolution RCMs that lead to late afternoon thunderstorms driven by the convergence of sea-breeze fronts in the centre of tropical islands and the Florida peninsula.

In the following section, we will show to what extent different mesoscale processes over Florida and the Caribbean are improved in CRCM5 simulations at increasing resolutions. Figure 13 presents the June-July-August (JJA) precipitation long-term climatology from the CRCM5 simulations, ERAI and different observationally-based gridded datasets over southeastern United States and the Caribbean. Only available over the United States, STAGE IV (Lin and Mitchell 2005) is an hourly 4-km mesh precipitation analysis based on radar estimates that are bias-corrected using rain-gage data. Global Climatology Precipitation Project (GPCP; Huffman et al. 2001) is a $1^{\circ}$-mesh daily global precipitation estimate based on geostationary infrared satellite data along with direct gauge measurements over land. 

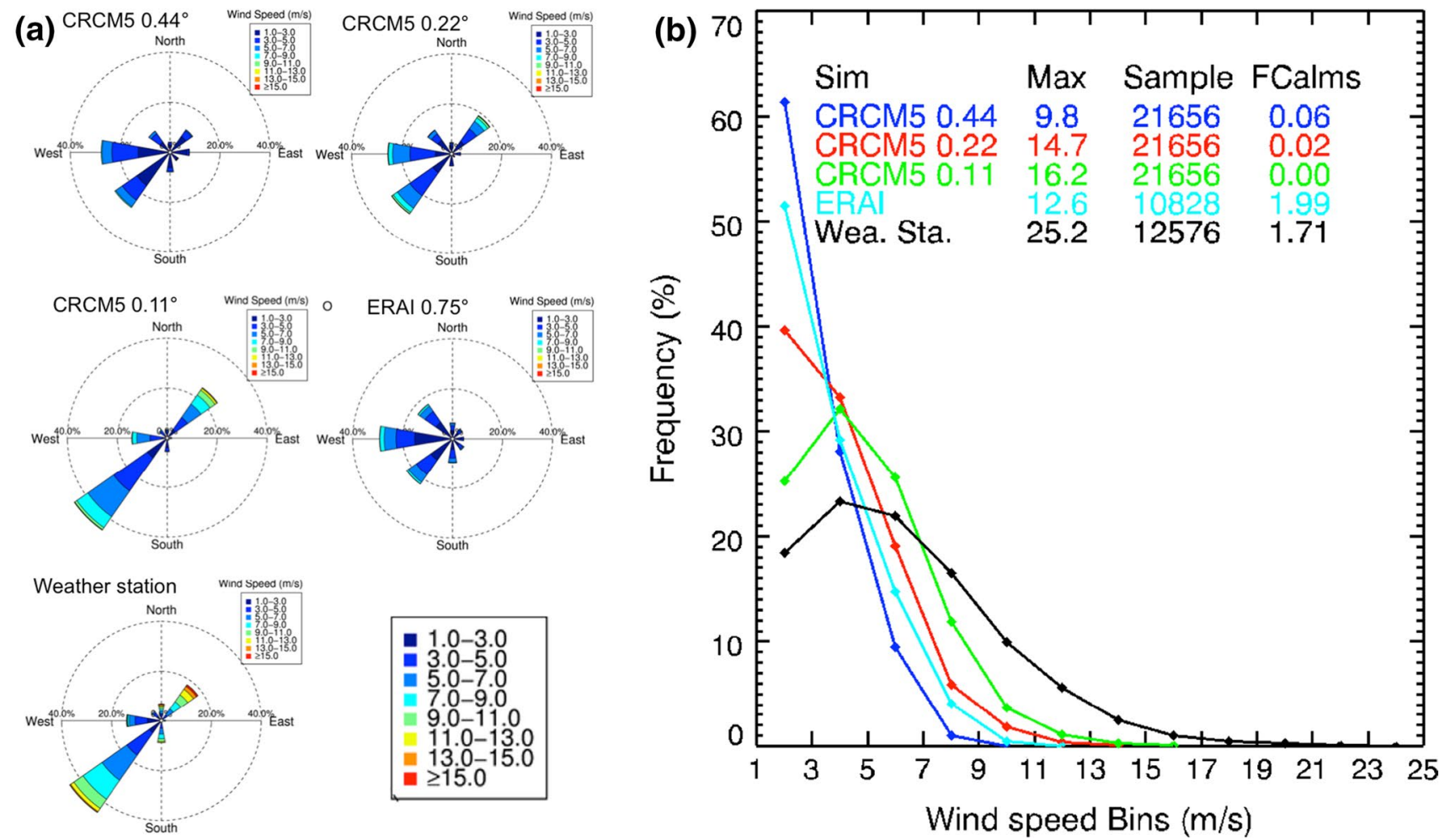

Fig. 12 1981-2010 DJF 10-m a wind rose and $\mathbf{b}$ wind speed intensity distribution of the closest grid cell of the CRCM5 simulations, ERAI and the weather station of Île d'Orléans

With increasing resolution, the CRCM5 seems to overestimate JJA precipitation over southern Florida. Most of the gridded observations (CRU, CONUS, TRMM and GPCP) have similar summer precipitation, except STAGE IV that shows more precipitation over southern Florida. With its finer mesh, TRMM shows higher precipitation over Cuba, Haiti and the Dominican Republic than GPCP and CRU. Likely due to its inability to resolve mesoscale processes, ERAI does not show high precipitation amounts over the islands. On the other hand, the CRCM5 simulations show high precipitation amounts over the islands that are in good agreement with precipitation from TRMM.

Precipitation over Florida and the Caribbean in summer is closely linked to the sea-breeze front inland movement and convergence that leads to the cumulus merger and ultimately thunderstorms in the afternoon. Sea breeze occurs when surface air pressure differences are created between the land and the ocean due to their different heat capacity. With its lower heat capacity, the land warms up quickly during the day and reaches, in the afternoon, a higher temperature than the ocean that is colder because of the larger heat capacity of the water. As a result, the warm air above the land tends to rise, creating a low-pressure region that is filled by the colder air above the sea. Once the land cools down during the night, the opposite process takes place with the colder air above the land moving toward the ocean where the water surface is warmer.

The weather phenomena described above take place every day in summer over the small Caribbean islands, sometimes with a diameter of only few tens of kilometers, and over the Florida peninsula that is around $200 \mathrm{~km}$ wide. Due to their coarse resolutions, GCMs and reanalyses can not represent adequately some small islands in their landsea mask and can not resolve properly the breezes and the cumulus merger that occur at the local scale (Qian 2008; Stefanova et al. 2012). For these reasons, precipitation from GCMs and reanalyses is most of the time underestimated over islands as can be seen in Fig. 13 for ERAI. In addition, without a good representation of the breezes, the diurnal cycle from ERAI over the islands is shifted with a daily maximum in the early afternoon (Fig. 14). Conversely, the diurnal cycle of the CRCM5 simulations over the islands are comparable to that from STAGE IV and TRMM. It should be noted that CRCM5 $0.11^{\circ}$ produces excessive precipitation during the period 20-01 Local Standard Time (LST), likely because the subgrid-scale parameterization tuned for coarser grid spacing was not modified for finer resolutions.

To verify the sea-breeze inland movement and convergence that produce precipitation progressively toward the 
Fig. 13 1981-2010 JJA precipitation (mm/day) over Florida and the Caribbean. STAGE IV, TRMM and GPCP cover shorter time periods as indicated
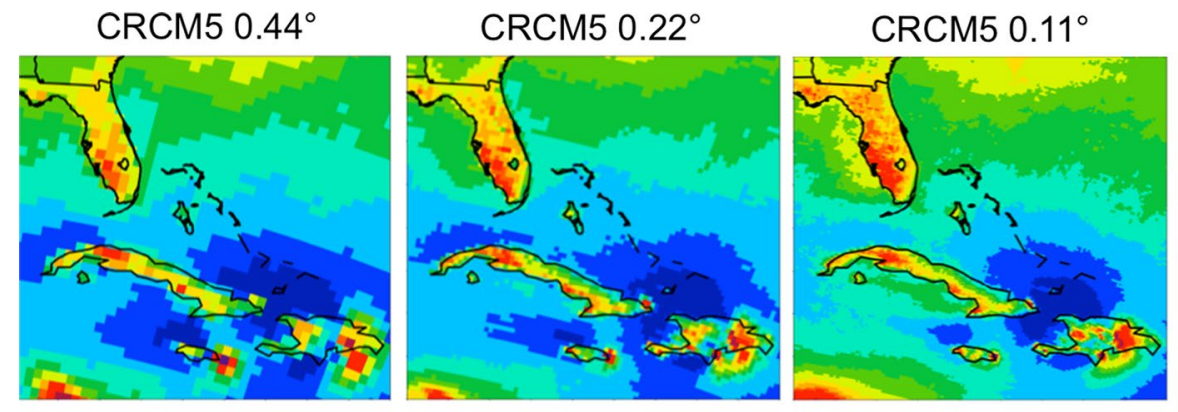

20
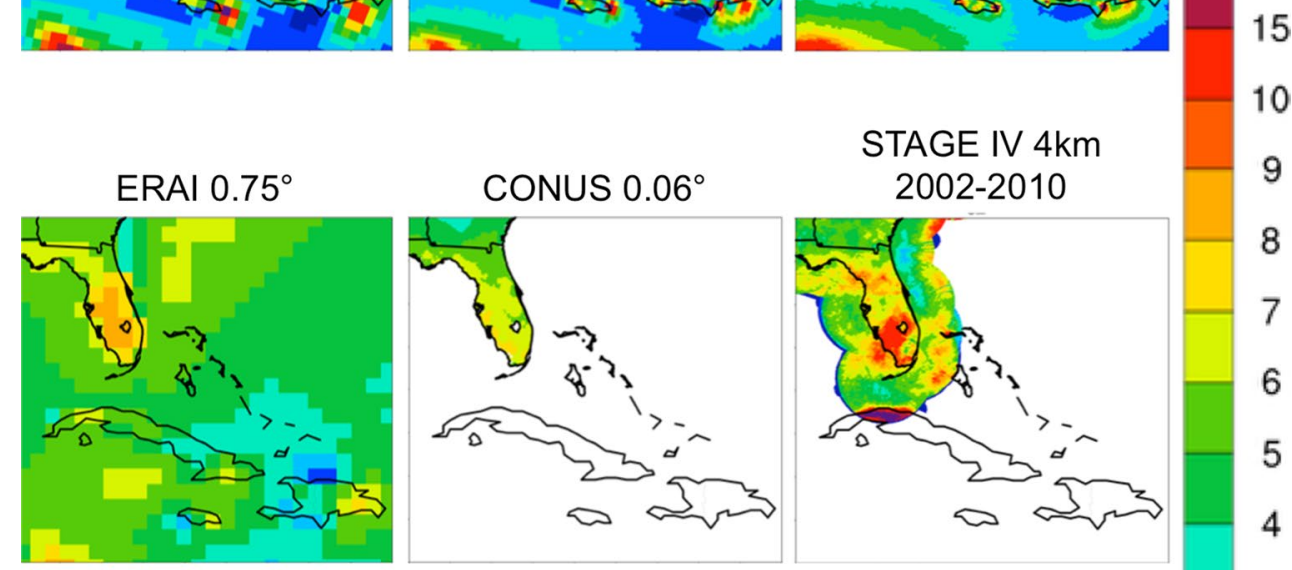

10

9

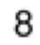

7

6

5

4

3

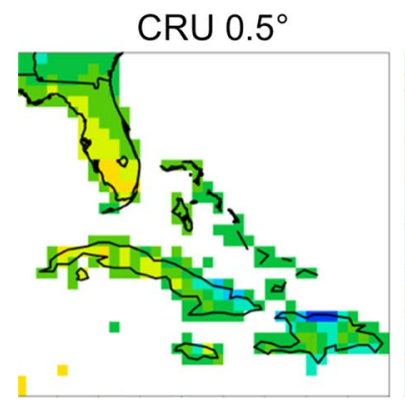

TRMM $0.25^{\circ}$

1998-2010
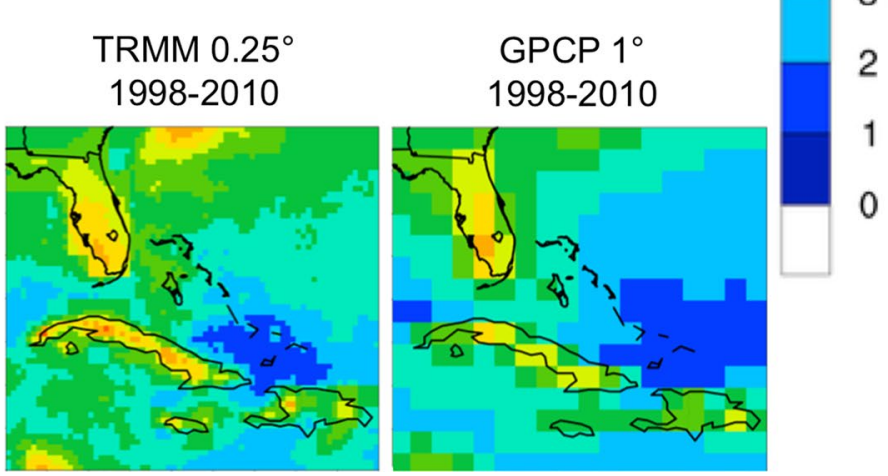

centre of the Florida peninsula and the islands, Fig. 15 shows the timing of the diurnal precipitation maximum in summer. At $0.44^{\circ}$, CRCM5 seems too coarse to simulate well the progression of the timing of the precipitation maximum toward the centre of the Florida peninsula and the islands. At $0.22^{\circ}$, the precipitation maximum timing over the coasts of Florida occurs at 15-16 LST, and then later on over the centre of Florida at $18-19$ LST. At $0.11^{\circ}$, there is also a clear progression of the precipitation maximum timing from the coasts toward the peninsula centre, but the signal seems to be perturbed by other local-scale processes. Indeed, as revealed by Boybeyi and Raman (1992), due to the presence of lakes that produce their own breeze atmospheric circulation, a cloudless region is present over lake Okeechobee until at least late afternoon. Also, only the $0.11^{\circ}$ CRCM5 simulation is able to simulate a physically plausible diurnal precipitation maximum at around 18-19 LST over the centre of Cuba. CRCM5 $0.22^{\circ}$ and $0.11^{\circ}$ are comparable to STAGE IV, which also shows a progression of the maximum diurnal precipitation timing toward the inner Florida peninsula.

Figure 16 highlights the mean annual cycle, mean diurnal cycle and distribution of precipitation intensities for different cities and the South Florida region. In general, the CRCM5 simulations overestimate precipitation over South Florida, except on the coasts in summer, as indicated by the city of Melbourne, where CRCM5 $0.11^{\circ}$ and $0.22^{\circ}$ are closer to CRU and CONUS than CRCM5 0.44 . The diurnal cycles from the CRCM5 simulations are in better agreement with TRMM and STAGE IV as the resolution increases. For the diurnal cycle, the rise and the maximum of precipitation from ERAI is clearly too early compared to the observations. The later diurnal precipitation maximum of Mountain Lake compared to Melbourne is well simulated by the CRCM5 simulations. The distribution of precipitation intensities and especially the most intense rainfalls are 


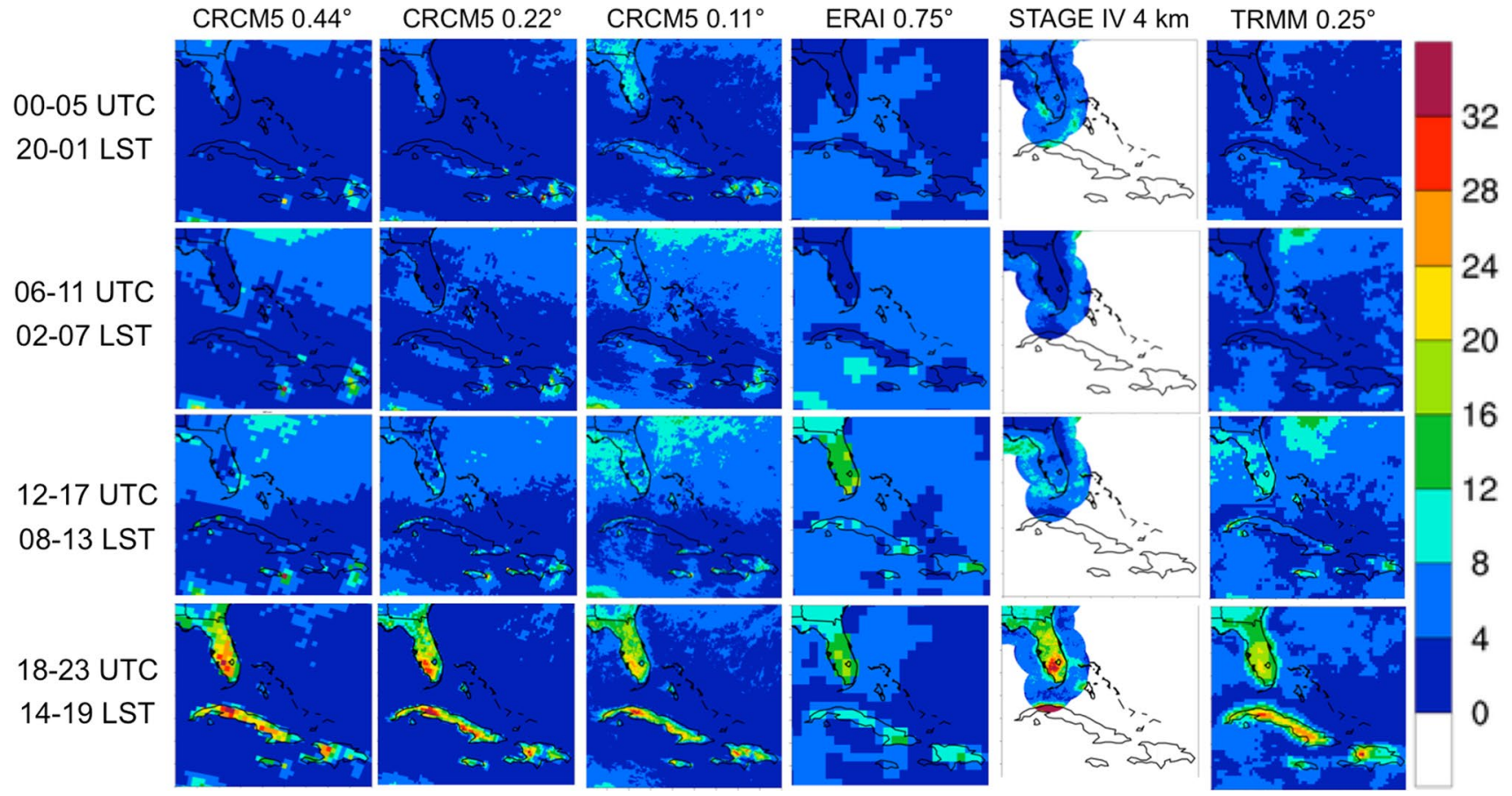

Fig. 14 2002-2010 6-hourly precipitation (mm/day) over Florida and the Caribbean

better simulated at $0.11^{\circ}$ with the CRCM5. CRCM5 0.44 and ERAI simulate too many medium-intensity precipitation events and too few high-intensity ones, likely due to their inability to represent essential small-scale processes to simulate heavy rain. For the precipitation intensities and the mean annual cycle, CONUS and the weather station (Wea. Sta.) are in good agreement, except that CONUS underestimates high precipitation intensities for Mountain Lakes. Generally, TRMM and STAGE IV have similar diurnal cycles.

In Fig. 17, wind vectors at 08 and 20 LST indicate regions affected by land or sea breezes. The daily mean wind speed and direction were subtracted from the instantaneous values to emphasize wind anomalies representing breezes. As anticipated, the coasts are affected by sea breezes in the early evening (20 LST) and land breezes in the early morning (08 LST). The breezes over Cuba, not simulated by ERAI, are stronger with the resolution increase for the CRCM5 simulations, and more smallscale features are simulated at $0.11^{\circ}$. BSW also indicates the large-scale breeze patterns, but the details are limited due to the relatively coarse resolution of NCEP reanalysis 2 , with a grid spacing of $1.875^{\circ}$, that provides wind directions to BSW.

In order to demonstrate that the breezes from CRCM5 are more realistic, the wind roses from the Sarasota and Melbourne weather stations and from the closest grid cell are shown in Fig. 18 at different times of the day. For Sarasota, the westerly sea breeze is well simulated by the CRCM5 simulations with a higher wind frequency from the west in the early evening (20 LST). Twelve hours later, the land breeze from the east in the morning (08 LST) is also well simulated by the CRCM5 simulations, but the frequency from CRCM5 $0.11^{\circ}$ matches better the one of the weather station. In the case of Melbourne, the easterly sea breeze in the afternoon (14 LST) is well simulated by the CRCM5 simulations with a dominant wind frequency from the east, also better at $0.11^{\circ}$. The high wind frequency mainly from the south during the night (02 LST), reproduced by the CRCM5 simulations, does not reflect clearly the land breeze toward the sea, which is likely influenced by other local forcings such as the orography and lakes, and also by the large-scale easterlies. CRCM5 $0.11^{\circ}$ wind directions and intensities are generally the most similar to both weather stations. According to its wind roses, ERAI is not able to represent appropriately breezes at different moments of the day on both coasts of Florida, probably a consequence of its coarse resolution and 6-h data assimilation system reinitializations. In summary, the CRCM5 simulations with finer resolutions show added value with an improved representation of the sea-breeze convergence and cumulus merger that produce most of the summer precipitation in the late afternoon over the Florida peninsula and the Caribbean islands. 
Fig. 15 Timing (LST) of the 2002-2010 JJA maximum diurnal precipitation over Florida and the Caribbean
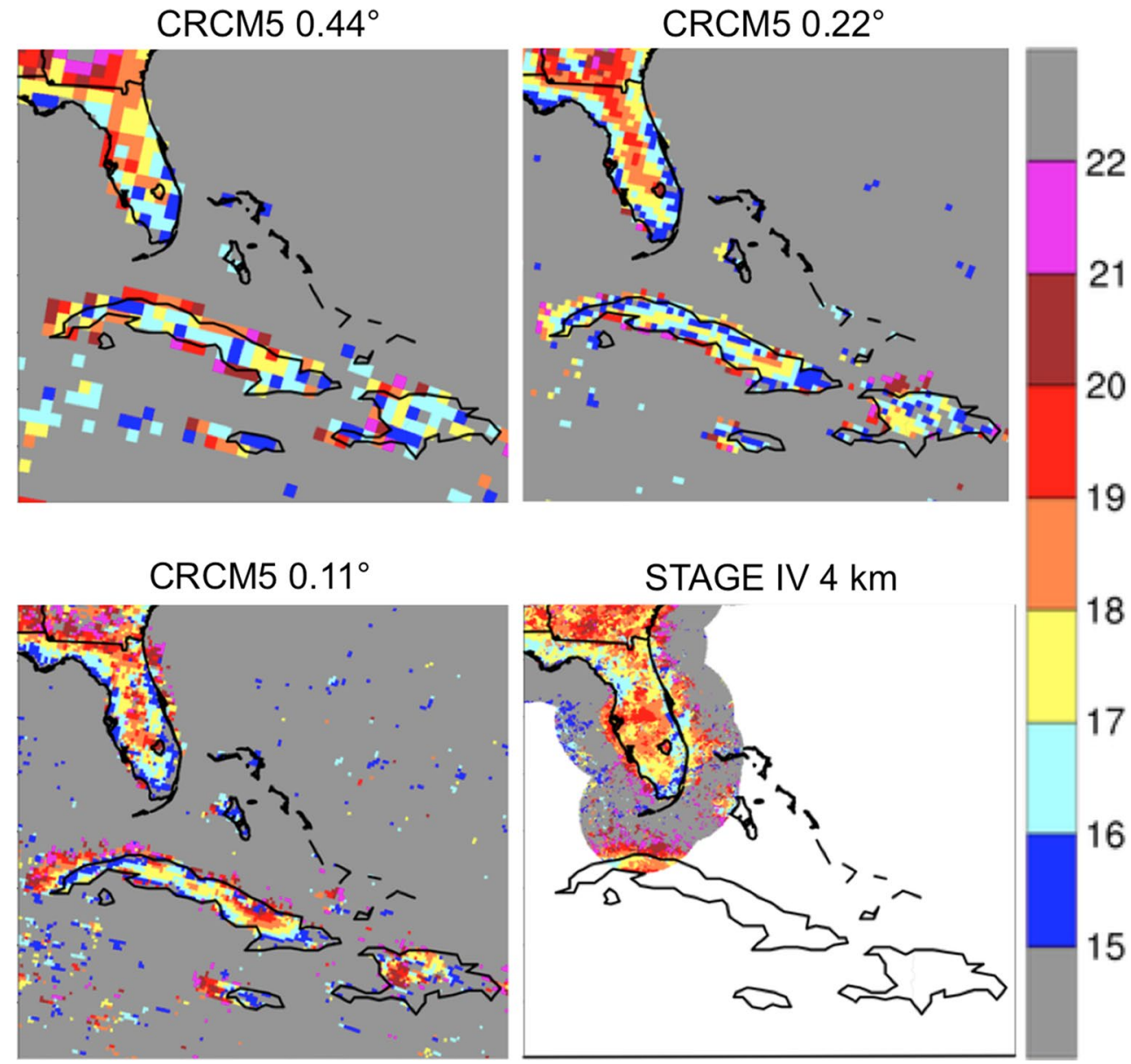

\section{Conclusions}

With the use of finer horizontal resolution, regional climate models (RCMs) are expected to add fine-scale details compared to their coarse-resolution driving model. But for these to represent an added value, their realism and quality need to be assessed. Recently, new high-resolution gridded datasets of common weather variables such as temperature and precipitation, but also from more "exotic" variables such as $10-\mathrm{m}$ wind and snow water equivalent, have emerged and they could help to identify added value in finer-resolution RCM simulations. In this paper, different weather phenomena were evaluated and shown to be improved at higher resolution using the fifth-generation Canadian RCM (CRCM5) over North America, with a grid spacing of $0.44^{\circ}, 0.22^{\circ}$ and $0.11^{\circ}$, driven at the lateral boundaries by the ERA-Interim (ERAI) reanalysis.

To begin, the evaluation of the long-term climatology of 2-m temperature and precipitation confirmed the satisfactory performance of the CRCM5, which showed no major systematic biases and little sensitivity to the reduction of the time steps. On the other hand, the large-scale long-term mean of $2-\mathrm{m}$ temperature and precipitation from the $0.11^{\circ}$
CRCM5 simulation did not seem superior to that of the $0.44^{\circ}$ simulation or ERAI.

The first weather phenomenon to be evaluated in this paper was the orographic precipitation in winter on the west coast of North America. As shown with a cross section, with the higher and sharper mountains at finer resolutions, the orographic precipitation by CRCM5 $0.11^{\circ}$ and $0.22^{\circ}$ is enhanced compared to CRCM5 $0.44^{\circ}$ and ERAI. Two rain bands, similar to the gridded observations, were simulated by the CRCM5 $0.11^{\circ}$ and $0.22^{\circ}$ compared to only one by CRCM5 $0.44^{\circ}$ and ERAI. With more precipitation and colder conditions at the top of the higher mountains of the finer simulations, the February CRCM5 $0.11^{\circ}$ snow water equivalent was the closest to the NOAA's National Snow Analysis (NSA).

The second weather phenomenon, the North American monsoon was evaluated to identify whether finer resolutions improved the precipitation amounts, cycles and intensities. Indeed, the finer resolution CRCM5 simulations produced more precipitation and were closer to the gridded observation in July-August-September. Moreover, the diurnal cycle and the more frequent precipitation extremes of the CRCM5 simulations were closer to the observations, 


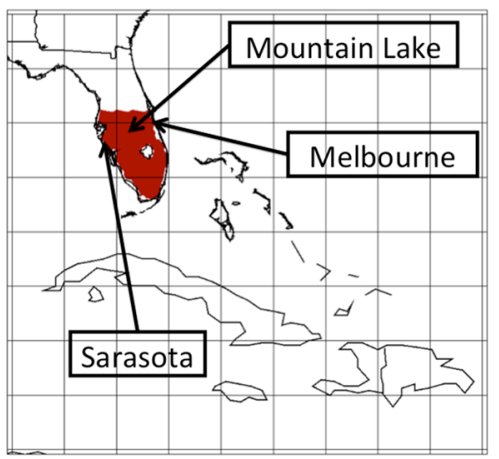

(a)

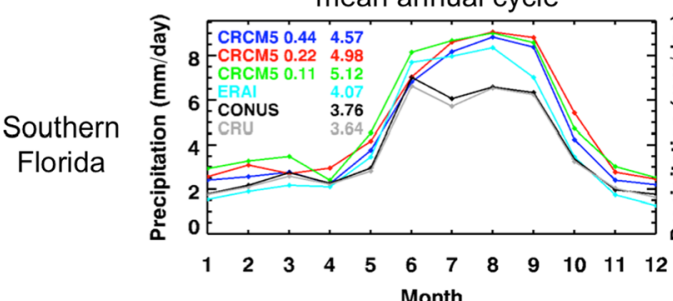

(b)

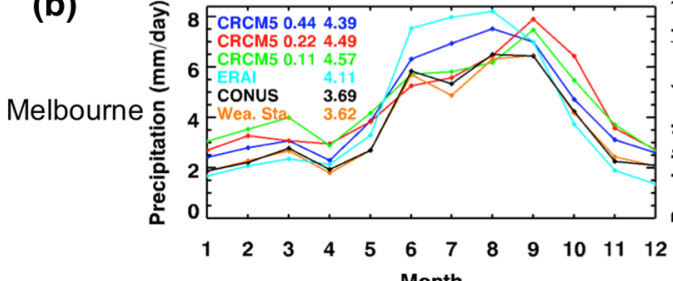

(c)

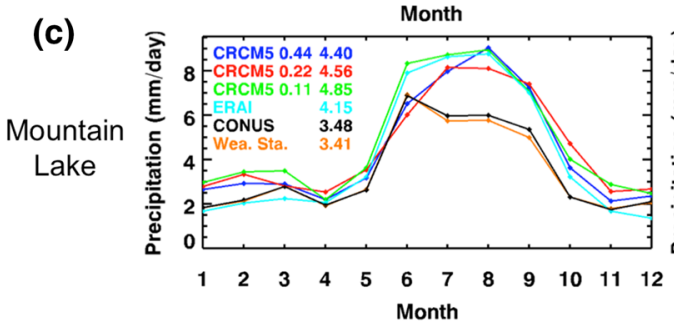

$1981-2010$

mean annual cycle

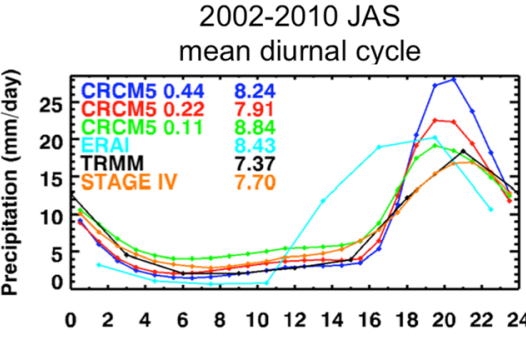

Hour (UTC)

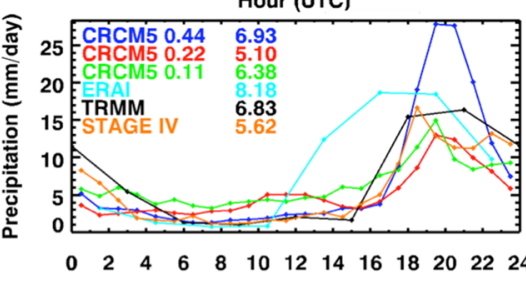

Hour (UTC)

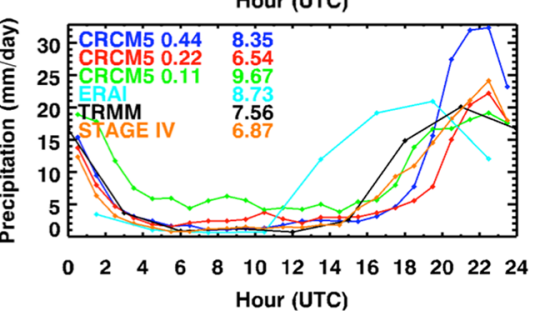

1981-2010 JAS distr. of precipitation intensities
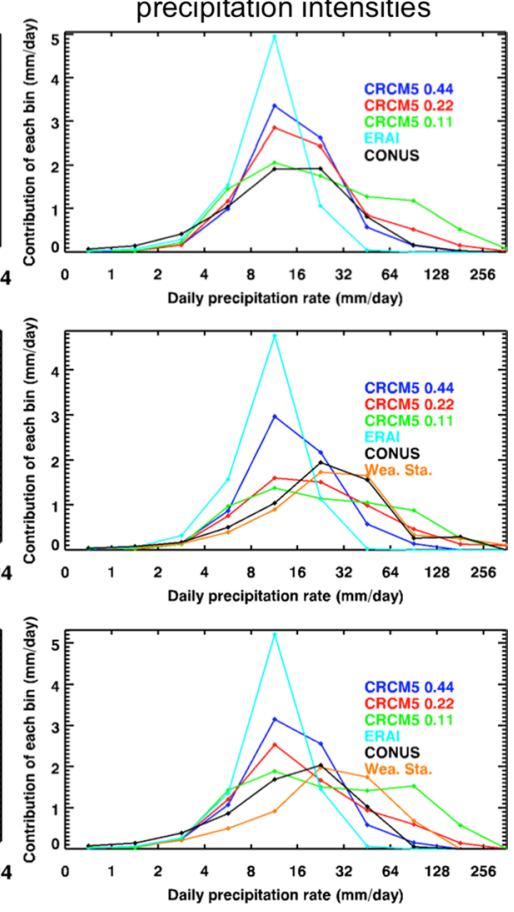

Fig. 16 Mean annual cycle, mean diurnal cycle and distribution of precipitation intensities over. a Southern Florida and $\mathbf{b}$ the Melbourne and $\mathbf{c}$ Mountain Lake weather stations. The numbers next to the data

likely because the CRCM5 was able to simulate mesoscale convective systems compared to ERAI. Also, using a Hovmöller diagram, the northward propagation and the longer lasting monsoon season of CRCM5 $0.22^{\circ}$ and $0.11^{\circ}$ seemed more realistic.

The third weather phenomenon to be evaluated is the lake-effect snow that leads to snowbelts in the vicinity of the Great Lakes. Indeed, the CRCM5 took advantage of the better lake delimitation and its improved ability to produce local-scale snow on the downwind lakeshores. As a result, only the CRCM5 $0.22^{\circ}$ and $0.11^{\circ}$ simulations showed distinct snowbelts on the south and east shores of Lake Superior and on the east of Lake Ontario that are comparable to these of NSA. CRCM5 $0.11^{\circ}$ showed additional added sources for the mean annual cycle and the mean diurnal cycle correspond to the annual mean and daily mean, respectively. The south Florida region is indicated in red

value to the east of the Great Lakes with snowy conditions in the Adirondack and Green Mountains contrasting with the dryer Lake Champlain Valley.

The fourth weather phenomenon to be explored is the wind channelling caused by the complex orography of St. Lawrence River Valley. Using gridded wind estimates from satellite data, the evaluation of the mean and extreme winds in fall from the CRCM5 simulations showed that the spatial distribution of the wind is improved at finer resolutions, likely due to the more precise coastline and orography. The comparison of the wind roses from the CRCM5 simulations and the weather station at Île d'Orléans confirmed that the dominant wind frequency along the southwest and northeast axis in winter is well simulated only by CRCM5 $0.11^{\circ}$. 
Fig. 17 2002-2010 20 LST and 08 LST JJA 10-m wind speed $(\mathrm{m} / \mathrm{s})$ and direction over Florida and the Caribbean. The daily mean is subtracted to highlight the anomalies. The colour scale and vector length indicate the wind speed $(\mathrm{m} / \mathrm{s})$ while the vector direction indicates the wind orientation

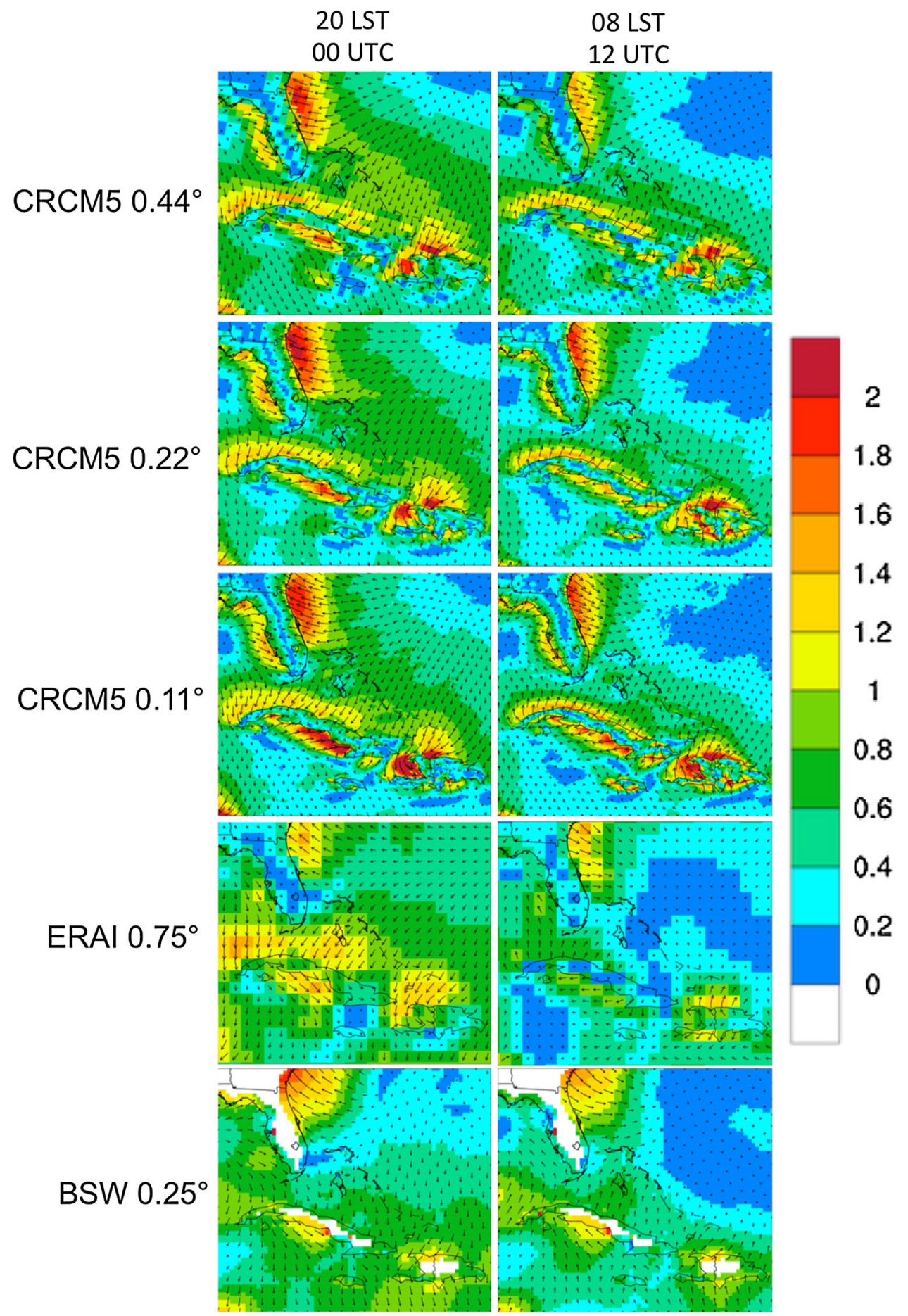

The last weather phenomenon to be evaluated was the precipitation associated with the sea-breeze convergence in the late afternoon in summer, over the Florida peninsula and the Caribbean islands. The finer resolution simulations showed distinct added value, with more precipitation over the islands than over the sea, a feature seen in the gridded observations. The timing of the maximum diurnal precipitation, showing the inland progression of the sea-breeze front, was clearly better for the $0.22^{\circ}$ and $0.11^{\circ}$ CRCM5 simulations. Finally, wind roses of two weather stations indicated that the $0.11^{\circ}$ simulation captured better the sea and land breezes at different periods of the day on the coasts of Florida.

To sum up, as the resolution increases with grid meshes of $0.44^{\circ}, 0.22^{\circ}$ and $0.11^{\circ}$, the simulation of weather phenomena showed almost all the time more added value. Only 


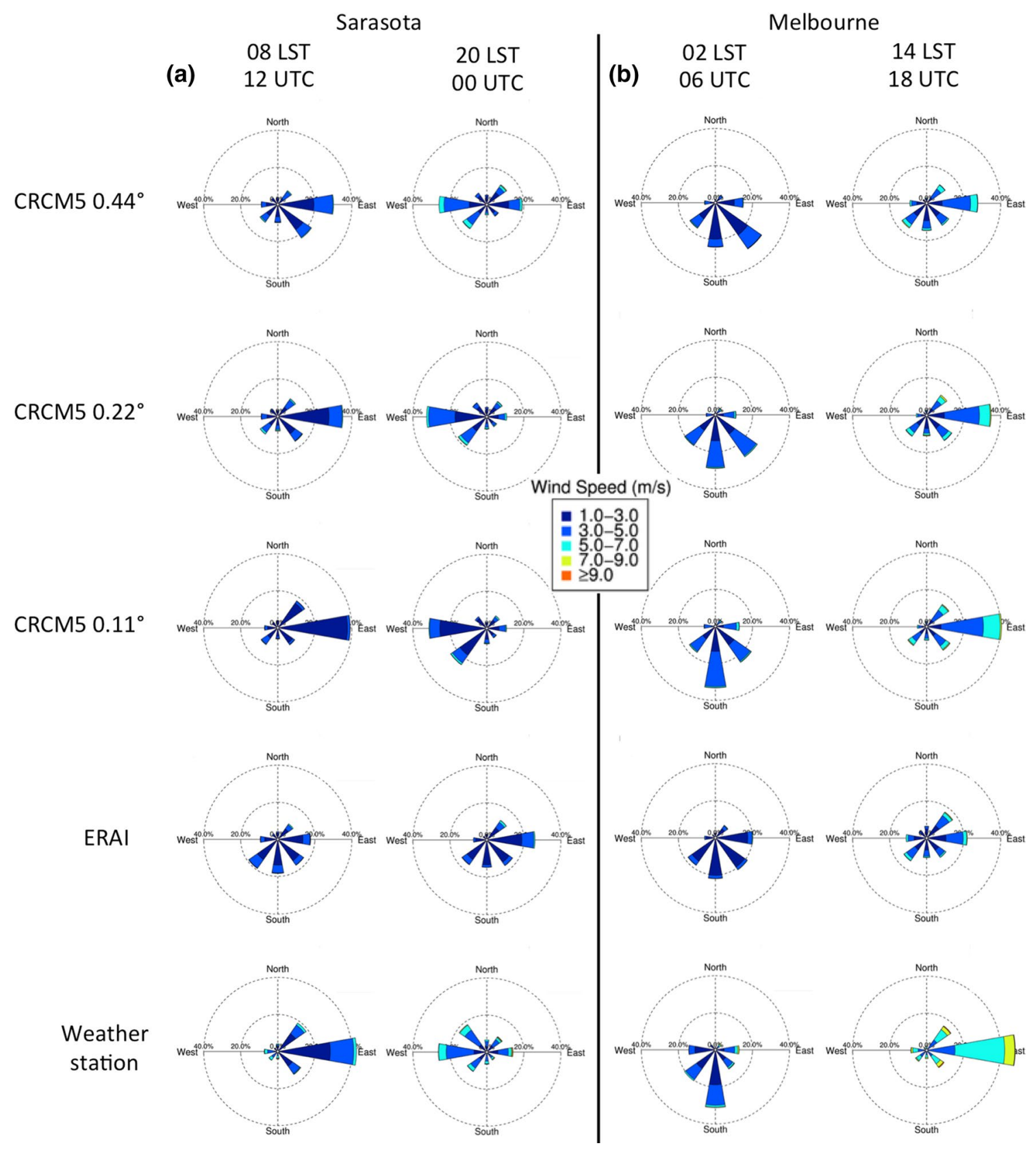

Fig. 18 1981-2010 JJA 10-m wind roses of a the Sarasota weather station at 08 LST and 20 LST and b the Melbourne weather station at 02 LST and 14 LST, for the closest grid cells of the CRCM5 simulations, ERAI and the weather station

in rare cases, the $0.11^{\circ}$ CRCM5 simulation was further away from the observations than the coarser resolution simulations. This counterintuitive behaviour could be explained by the choice to use of the same subgrid-scale parameterizations at all resolutions to focus on the added value linked exclusively to the resolution increase. In order to get optimal results at $0.11^{\circ}$, the parameterizations should be tuned for higher resolutions. Even with the recent improvements, observationally-based gridded datasets suffer of the lack of stations in remote regions, explaining why sometimes added value of finer resolution simulations can not be validated. It is reasonable to believe that in certain cases, the RCM simulations represented better the reality than the gridded observations. Alternatively, the use of time series from individual weather stations was useful to confirm added value from finer resolution RCM simulations. However, this can be tricky because weather stations sometimes reflect very local effects that may give wrong impressions when compared to model grid point values representing spatial averages of several $\mathrm{km}^{2}$ (Lucas-Picher et al. 2012). 
One should keep in mind that the RCM hindcast simulations in this study are driven at their lateral boundaries by a reanalysis, in which the large-scale atmospheric forcing is assumed to be close to reality due to the assimilated observations. Thus, the added value identified from an RCM using a reanalysis at its lateral boundaries is a first necessary step, but not a sufficient one towards the identification of added value in RCM simulations driven by GCM climate-change projections that can be of use in IPCC reports. To justify the use of RCMs for climatechange projections, added value should also be verified in RCM simulations driven by boundary conditions from GCM simulations that contain some level of errors, in the atmosphere, but also in the sea-surface conditions (Hernández-Díaz et al. 2016). Thus, additional studies on examples of RCM added value are needed, especially in a context where boundary conditions come from GCM simulations. Finally, the more obvious added value at finer resolutions suggest that higher resolutions, affordable only over smaller domains, might get a higher priority to promote regional climate modelling added value. The use of smaller domains that permit higher resolutions at a reasonable computational cost has recently been put forward through flagship pilot studies to promote the use of RCMs (Giorgi and Gutowski 2015).

\begin{abstract}
Acknowledgments This study was supported by funding from the project "Marine Environmental Observation, Prediction and Response" (MEOPAR) of the Network of Centres of Excellence (NCE) of Canada and the "Climate Change and Atmospheric Research" (CCAR) programme of the Natural Sciences and Engineering Research Council of Canada (NSERC) through a grant to the Canadian Network for Regional Climate and Weather Processes (CNRCWP). The calculations were made possible through Compute Canada-Calcul Québec supercomputers.
\end{abstract}

Open Access This article is distributed under the terms of the Creative Commons Attribution 4.0 International License (http://creativecommons.org/licenses/by/4.0/), which permits unrestricted use, distribution, and reproduction in any medium, provided you give appropriate credit to the original author(s) and the source, provide a link to the Creative Commons license, and indicate if changes were made.

\section{References}

Alexandru A, Sushama L (2015) Current climate and climate change over India as simulated by the Canadian Regional Climate Model. Clim Dyn 45:1059-1084. doi:10.1007/s00382-014-2350-y

Bélair S, Mailhot J, Girard C, Vaillancourt PA (2005) Boundary layer and shallow cumulus clouds in a medium-range forecast of a large-scale weather system. Mon Wea Rev 133:1938-1960. doi:10.1175/MWR2958.1

Bélair S, Roch M, Leduc A-M, Vaillancourt PA, Laroche S, Mailhot J (2009) Medium-range quantitative precipitation forecasts from Canada's new 33-km deterministic global operational system. Wea Forecast 24:690-708. doi:10.1175/2008WAF2222175.1
Bentamy A, Grodsky SA, Carton JA, Croizé-Fillon D, Chapron B (2012) Matching ASCAT and QuikSCAT winds. J Geophys Res 117:C02011. doi:10.1029/2011JC007479. ftp://podaac.jpl.nasa. gov/OceanWinds/quikscat/preview/L2B12/v3/

Boybeyi Z, Raman S (1992) A three-dimensional numerical sensitivity study of convection over the Florida peninsula. Bound-Layer Meteor 60:325-359

Brown RD, Brasnett B (2010) Canadian Meteorological Centre (CMC) Daily Snow Depth Analysis Data. (C) Environment Canada, 2010. National Snow and Ice Data Center, Boulder

Brown RD, Brasnett B, Robinson D (2003) Gridded North American monthly snow depth and snow water equivalent for GCM evaluation. Atmos Ocean 41:1-14

Bukovsky MS, Gochis DJ, Mearns LO (2013) Towards assessing NARCCAP regional climate model credibility for the North American Monsoon: current climate simulations. J Clim 26:8802-8826. doi:10.1175/JCLI-D-12-00538.1

Carroll T, Cline D, Olheiser C, Rost A, Nilsonn A, Fall G, Bovitz C, Li L (2006) NOAA's national snow analyses. Proceedings, 74th Western Snow Conference

Cholette M, Laprise R, Thériault JM (2015) Perspectives for very high-resolution climate simulations with nested models: illustration of potential in simulating St. Lawrence River Valley channelling winds with the fifth-generation. Can Reg Clim Model Clim 3:283-307. doi:10.3390/cli3020283

Collier JC, Zhang GJ (2007) Effects of increased horizontal resolution on simulation of the North American monsoon in the NCAR CAM3: an evaluation based on surface, satellite, and reanalysis data. J Clim 20:1843-1862

Côté J, Gravel S, Méthot A, Patoine A, Roch M, Staniforth A (1998) The operational CMC-MRB global environmental multiscale (GEM) model. Part I: design considerations and formulation. Mon Wea Rev 126:1373-1395

Dee DP et al (2011) The ERA-Interim reanalysis: configuration and performance of the data assimilation system. Q J R Meteorol Soc 137:553-597. doi:10.1002/qj.828

Di Luca A, de Elía R, Laprise R (2012) Potential for added value in precipitation simulated by high resolution nested Regional Climate Models and observations. Clim Dyn 38:1229-1247. doi:10.1007/s00382-011-1068-3

Di Luca A, de Elía R, Laprise R (2015) Challenges in the quest for added value of regional climate dynamical downscaling. Curr Clim Change Rep 1:10-21. doi:10.1007/s40641-015-0003-9

Douglas KW, Valdez-Manzanilla A, Garcia Cueto R (1998) Diurnal variations and horizontal extent of the low-level jet over the northern Gulf of California. Mon Wea Rev 126:2017-2025

Feser F (2006) Enhanced detectability of added value in limited area model results separated into different spatial scales. Mon Wea Rev 134:2180-2190. doi:10.1175/MWR3183.1

Feser F, Rockel B, von Storch H, Winterfeldt J, Zahn M (2011) Regional climate models add value to global model data: a review and selected examples. Bull Am Meteorol Soc 92:11811192. doi:10.1175/2011BAMS3061.1

Flato G (2013) Evaluation of climate models. In: Stocker TF, Qin D, Plattner G-K, Tignor M, Allen SK, Boschung J, Nauels A, Xia Y, Bex V, Midgley PM et al (eds) Climate Change 2013: The Physical Science Basis. Contribution of Working Group I to the Fifth Assessment Report of the Intergovernmental Panel on Climate Change. Cambridge University Press, Cambridge

Giorgi F, Bates GT (1989) The climatological skill of a regional model over complex terrain. Mon Wea Rev 117:2325-2347

Giorgi F, Gutowski WJ (2015) Regional dynamical downscaling and the CORDEX initiative. Annu Rev Environ Resour 40:467-490

Giorgi F, Jones C, Asrar GR (2009) Addressing climate information needs at the regional level: the CORDEX framework. WMO Bull $58: 175-183$ 
Gutzler DS et al (2005) The North American Monsoon Model Assessment Project: integrating numerical modeling into a field-based process study. Bull Am Meteorol Soc 86:1423-1429

Harris I, Jones PD, Osborn TJ, Lister HD (2014) Updated high-resolution grids of monthly climatic observations- the CRU TS3.10 Dataset. Int J Climatol 34:623-642. doi:10.1002/joc.3711

Haylock MR, Hofstra N, Klein Tank AMG, Klok EJ, Jones PD, New M (2008) A European daily high-resolution gridded dataset of surface temperature and precipitation. J Geophys Res 113:D20119. doi:10.1029/2008JD10201

Hernández-Díaz L, Laprise R, Sushama L, Martynov A, Winger K, Dugas B (2013) Climate simulation over the CORDEX-Africa domain using the fifth-generation Canadian Regional Climate Model (CRCM5). Clim Dyn 40:1415-1433. doi:10.1007/ s00382-012-1387-z

Hernández-Díaz L, Laprise R, Nikiéma O, Winger K (2016) 3-Step dynamical downscaling with empirical correction of sea-surface conditions: application to a CORDEX Africa simulation. Clim Dyn. doi:10.1007/s00382-016-3201-9

Herrmann M, Somot S, Calmanti S, Dubois C, Sevault F (2011) Representation of spatial and temporal variability of daily wind speed and of intense wind events over the Mediterranean Sea using dynamical downscaling: impact of the regional climate model configuration. Nat Hazards Earth Syst Sci 11:1983-2001. doi:10.5194/nhess-11-1983-2011

Hong SY, Kanamitsu M (2014) Dynamical downscaling: fundamental issues from an NWP point of view and recommendations. Asia Pacific J Atmos Sci 50:83-104. doi:10.1007/s13143-014-0029-2

Huffman GJ, Bolvin DT (2011) TRMM and other data precipitation data set documentation. ftp://precip.gsfc.nasa.gov/pub/ trmmdocs/3B42_3B43_doc.pdf

Huffman GJ, Adler RF, Morrissey MM, Curtis S, Joyce R, McGavock B, Susskind J (2001) Global precipitation at one-degree daily resolution from multisatellite observations. J Hydrometeorol 2:36-50

Huffman GJ, Adler RF, Bolvin DT, Gu G, Nelkin EJ, Bowman KP, Hong Y, Stocker EF, Wolff DB (2007) The TRMM multisatellite precipitation analysis: quasi-global, multiyear, combined-sensor precipitation estimates at fine scale. J Hydrometeorol. 8:38-55

Hutchinson M, Mckenney DW, Lawrence K, Pedlar JH, Hopkinson RF, Milewska E, Papadopol P (2009) Development and testing of Canada-wide interpolated spatial models of daily minimummaximum temperature and precipitation for 1961-2003. J Appl Meteorol Climatol 48:725-741. doi:10.1175/2008JAMC1979.1

Jacob D et al (2014) EURO-CORDEX: new high-resolution climate change projections for European impact research. Reg Environ Change 14:563-578

Klehmet K, Geyer B, Rockel B (2013) A regional climate model hindcast for Siberia: analysis of snow water equivalent. The Cryosphere 7:1017-1034. doi:10.5194/tc-7-1017-2013

Kotlarski S et al (2014) Regional climate modeling on European scales: a joint standard evaluation of the EURO-CORDEX RCM ensemble. Geosci Model Dev 7:1297-1333. doi:10.5194/ gmd-7-1297-2014

Laprise R, Hernández-Díaz L, Tete K, Sushama L, Šeparović L, Martynov A, Winger K, Valin M (2013) Climate projections over CORDEX Africa domain using the fifth-generation Canadian Regional Climate Model (CRCM5). Clim Dyn 41:3219-3246. doi:10.1007/s00382-012-1651-2

Leung LR, Qian Y (2003) The sensitivity of precipitation and snowpack simulations to model resolution via nesting in regions of complex Terrain. J Hydrometeorol 4:1025-1043. doi:10.1175/1525-7541(2003)004<1025:TSOPAS >2.0.CO;2

Leung LR, Mearns LO, Giorgi F, Wilby RL (2003) Regional Climate Research. Bull Am Meteorol Soc 84:89-95. doi:10.1175/ BAMS-84-1-89
Li D (2016) Added value of high-resolution regional climate model: selected cases over the Bohai Sea and the Yellow Sea areas. Int J Climatol. doi:10.1002/joc.4695

Lin Y, Mitchell KE (2005) The NCEP stage II/IV hourly precipitation analyses: Development and applications. Preprints, 19th conference on Hydrology, San Diego, CA, 708 Am. Meteor. Soc., 1.2

Livneh B, Rosenberg EA, Lin C, Nijssen B, Mishra V, Andreadis KM, Maurer EP, Lettenmaier DP (2013) A long-term hydrologically based dataset of land surface fluxes and states for the conterminous united states: update and extensions. J Clim 26:9384-9392. doi:10.1175/JCLI-D-12-00508.1

Lucas-Picher P, Wulff-Nielsen M, Christensen JH, Aðalgeirsdóttir G, Mottram R, Simonsen SB (2012) Very high resolution regional climate model simulations over Greenland: identifying added value. J Geophys Res 117:D02108. doi:10.1029/2011JD016267

Lucas-Picher P, Riboust P, Somot S, Laprise R (2015) Reconstruction of the Spring 2011 Richelieu river flood by two regional climate models and a hydrological model. J Hydrometeorol 16:36-54. doi:10.1175/JHM-D-14-0116.1

Martynov A, Sushama L, Laprise R, Winger K, Dugas B (2012) Interactive lakes in the Canadian Regional climate model, version 5: the role of lakes in the regional climate of North America. Tellus A 64:16226. doi:10.3402/tellusa.v64i0.16226

Martynov A, Laprise R, Sushama L, Winger K, Šeparović L, Dugas B (2013) Reanalysis-driven climate simulation over CORDEX North America domain using the Canadian Regional Climate Model, version 5: model performance evaluation. Clim Dyn 41L:2973-3005. doi:10.1007/s00382-013-1778-9

Maurer EP, Wood AW, Adam JC, Lettenmaier DP, Nijssen B (2002) A long-term hydrologically-based dataset of land surface fluxes and states for the conterminous United States. J Clim 15:32373251. doi:10.1175/1520-0442(2002)015<3237:ALTHBD>2.0. $\mathrm{CO} ; 2$

Panitz H-J, Dosio A, Büchner M, Lüthi D, Keuler K (2013) COSMOCLM (CCLM) climate simulations over CORDEX Africa domain: analysis of the ERA-Interim driven simulations at $0.44^{\circ}$ and $0.22^{\circ}$ resolution. Clim Dyn 42:3015-3038. doi:10.1007/ s00382-013-1834-5

Qian JH (2008) Why precipitation is mostly concentrated over islands in the maritime continent. J Atmos Sci 65:1428-1441. doi:10.11 75/2007JAS2422.1

Rasmussen R et al (2011) High-Resolution coupled climate runoff simulations of seasonal snowfall over Colorado: a process study of current and warmer climate. J Clim 24:3015-3048. doi:10.11 75/2010JCLI3985.1

Roebber PJ, Gyakum JR (2003) Orographic Influences on the Mesoscale Structure of the 1998 Ice Storm. Mon Wea Rev 131:27-50

Rost A (2010) Snow board: A look at the importance of snow information. Meteorological Technology International, UKiP, Dorking, pp 26-29

Rummukainen M (2010) State-of-the-art with regional climate models. WIREs Clim Change 1:82-96. doi:10.1002/wcc.8

Salzmann N, Mearns LO (2012) Assessing the performance of multiple regional climate model simulations for seasonal mountain snow in the Upper Colorado River Basin. J Hydrometeorol 13:539-556. doi:10.1175/2011JHM1371.1

Šeparović L, Alexandru A, Laprise R, Martynov A, Sushama L, Winger K, Tete K, Valin M (2013) Present climate and climate change over North America as simulated by the fifth-generation Canadian Regional Climate Model (CRCM5). Clim Dyn 41:3167-3201

Stefanova L, Misra V, Chan S, Griffin M, O’Brien JJ, Smith JT III (2012) A proxy for high-resolution regional reanalysis for the southeast United States: assessment of precipitation variability in dynamically downscaled reanalyses. Clim Dyn 38:2449-2466. doi:10.1007/s00382-011-1230-y 
Takhsha M, Nikiéma O, Lucas-Picher P, Laprise R, Winger K (2016) Climate simulations and projection over CORDEX Arctic domain using CRCM5: Effects of large-scale spectral nudging and empirical correction of sea-surface temperature bias. Clim Dyn (in preparation)

Verseghy DL (2009) CLASS-The Canadian Land Surface Scheme (Version 3.4)-technical documentation (version 1.1). Internal report, Climate Research Division, Science and Technology Branch, Environment Canada, p 183. http://www.usask.ca/ip3/ download/CLASS_v3_4_Documentation_v1_1.pdf

Vidal J-P, Martin E, Franchistéguy L, Baillon M, Soubeyroux J-M (2010) A 50-year high-resolution atmospheric reanalysis over France with the Safran system. Int J Climatol 30:1627-1644. doi: $10.1002 /$ joc. 2003

Winterfeldt J, Weisse R (2009) Assessment of value added for surface marine wind speed obtained from two Regional Climate Models (RCMs). Mon Wea Rev 137:2955-2965. doi:10.1175/2009 MWR2704.1
Wright DM, Posselt DJ, Steiner AL (2013) Sensitivity of lakeeffect snowfall to lake ice cover and temperature in the Great Lakes region. Mon Wea Rev 141:670-689. doi:10.1175/ MWR-D-12-00038.1

Yatagai A, Kamiguchi K, Arakawa O, Hamada A, Yasutomi N, Kitoh A (2012) APHRODITE: constructing a long-term daily gridded precipitation dataset for asia based on a dense network of rain Gauges. Bull Am Meteorol Soc 93:1401-1415. doi:10.1175/ BAMS-D-11-00122.1

Zhang HM, Bates JJ, Reynolds RW (2006) Assessment of composite global sampling: Sea surface wind speed. Geophys Res Lett 33:L17714. doi:10.1029/2006GL027086. ftp://eclipse.ncdc. noaa.gov/pub/seawinds/ 